\title{
3-Hydroxy-propanamidines, a new class of orally active antimalarials targeting Plasmodium \\ falciparum
}

Tanja C. Knaab ${ }^{1}$, Jana Held 2,3, Bjoern B. Burckhardt ${ }^{4}$, Kelly Rubiano ${ }^{5}$, John Okombo ${ }^{5}$, Tomas

Yeo $^{5}$, Sachel Mok ${ }^{5}$,Anne-Catrin Uhlemann ${ }^{6}$, Beate Lungerich $^{1}$, Christoph Fischli ${ }^{7,8}$, Lais

Pessanha de Carvalho 2 , Benjamin Mordmüller2,3, Sergio Wittlin ${ }^{7,8}$, David A. Fidock ${ }^{5,6}$, Thomas

Kurz $^{l *}$

${ }^{1}$ Institute of Pharmaceutical and Medicinal Chemistry, Heinrich Heine University Düsseldorf, Universitätsstraße 1, 40225 Düsseldorf, Germany.

${ }^{2}$ Institute of Tropical Medicine, Eberhard Karls University Tübingen, Wilhelmstraße 27, 72074 Tübingen, Germany.

${ }^{3}$ Centre de Recherches Medicales de Lambaréné, B.P.: 242 Lambaréné, Gabon

${ }^{4}$ Institute of Clinical Pharmacy and Pharmacotherapy, Heinrich Heine University Düsseldorf, Universitätsstraße 1, 40225 Düsseldorf, Germany.

${ }^{5}$ Department of Microbiology \& Immunology, Columbia University Irving Medical Center, New York, NY 10032, USA

${ }^{6}$ Division of Infectious Diseases, Department of Medicine, Columbia University Irving Medical Center, New York, NY 10032, USA

${ }^{7}$ Swiss Tropical and Public Health Institute, Socinstraße 57, 4002 Basel, Switzerland

${ }^{8}$ University of Basel, CH-4003 Basel, Switzerland 


\section{Table of Content}

1. Synthesis and analytical data of starting materials ..................................................... 2

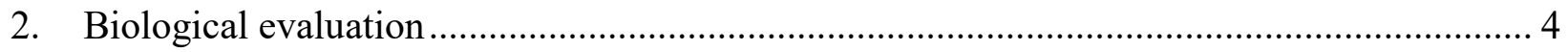

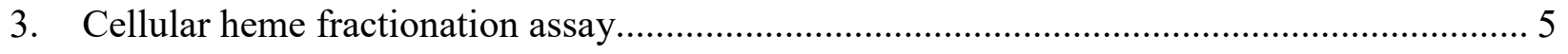

4. In vitro selection of resistance ................................................................................. 5

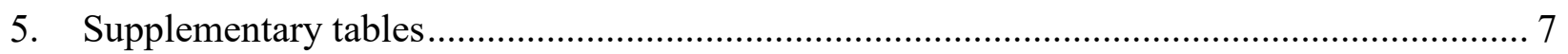

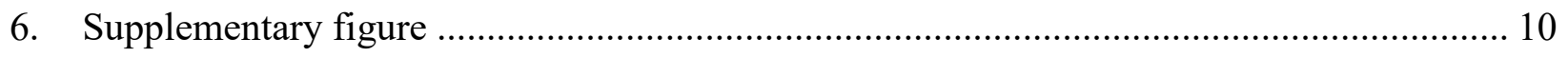

7. ${ }^{1} \mathrm{H}-,{ }^{13} \mathrm{C}$-Spectra and HPLC chromatograms of target compounds ................................ 11

\section{Synthesis and analytical data of starting materials}

Synthesis of starting materials 3d-h. In a two-necked flask $n$-butyllithium $(8.25 \mathrm{~mL}, 13.2 \mathrm{mmol}$ 1.6 $\mathrm{M}$ in $n$-hexane) was diluted in anhyd. THF $(10 \mathrm{~mL})$ at $-78{ }^{\circ} \mathrm{C}$ under inert gas atmosphere. Subsequently anhyd. acetonitrile $(0.63 \mathrm{~mL}, 12.0 \mathrm{mmol})$ diluted in anhyd. THF $(5 \mathrm{~mL})$ was added dropwise over a period of 5 minutes to the solution. The reaction mixture was stirred at $-78{ }^{\circ} \mathrm{C}$ for one hour while a white suspension was formed. Subsequently, the corresponding aldehyde (2d-h, $12.0 \mathrm{mmol})$, dissolved in anhyd. THF $(10 \mathrm{~mL})$, was slowly added to the suspension. After warming to $\mathrm{rt}$ while stirring for 15 minutes the resulted solution was poured to an ice-water mixture containing $10 \% \mathrm{HCl}$. The organic phase was separated and the aqueous phase was extracted with diethyl ether $(3 \times 50 \mathrm{~mL})$. The aqueous phase of the nitriles $\mathbf{3 g}$, $\mathbf{h}$ was adjusted to $\mathrm{pH} 8$ with sat. $\mathrm{NaHCO}_{3}$ solution before extraction. The combined organic phases were washed with a sat. sodium chloride solution, dried over anhyd. $\mathrm{Na}_{2} \mathrm{SO}_{4}$ and concentrated under reduced pressure. Purification by flash chromatography on silica gel using $n$-hexane/AcOEt ( 0 to $100 \%$ ) yield the desired products as white to light yellow solids. 
3-(Anthracen-9-yl)-3-hydroxypropanenitrile (3d) Light yellow solid, yield: $78 \%$, mp: $144{ }^{\circ} \mathrm{C}$, ${ }^{1} \mathrm{H}-\mathrm{NMR}\left(300 \mathrm{MHz}\right.$, DMSO- $\left.d_{6}\right) \delta[\mathrm{ppm}]=8.73(\mathrm{~d}, \mathrm{~J}=8.5 \mathrm{~Hz}, 2 \mathrm{H}), 8.61(\mathrm{~s}, 1 \mathrm{H}), 8.15-8.06(\mathrm{~m}$, 2H), 7.64-7.46 (m, 4H), 6.53-6.43 (m, 2H), 3.45-3.37 (m, 1H), 3.24-3.14 (m, 1H). ${ }^{13} \mathrm{C}-\mathrm{NMR}$ $\left(151 \mathrm{MHz}, \mathrm{DMSO}-d_{6}\right) \delta[\mathrm{ppm}]=133.57,131.61,129.59,129.21,128.63,126.29,125.46,119.33$, 65.63, 26.42. HPLC (Meth. 1): $t_{\mathrm{R}}=13.0 \mathrm{~min}, \mathrm{AUC} \geq 99 \%$.

3-(4-(tert-Butyl)phenyl)-3-hydroxypropanenitrile (3e) White solid, yield: $98 \%$, mp: $75{ }^{\circ} \mathrm{C}$, ${ }^{1} \mathrm{H}-\mathrm{NMR}\left(300 \mathrm{MHz}, \mathrm{DMSO}-d_{6}\right) \delta[\mathrm{ppm}]=7.42-7.30(\mathrm{~m}, 4 \mathrm{H}), 5.86(\mathrm{~d}, J=4.4 \mathrm{~Hz}, 1 \mathrm{H}), 4.85(\mathrm{dt}$, $J=6.7,4.8 \mathrm{~Hz}, 1 \mathrm{H}), 2.95-2.72(\mathrm{~m}, 2 \mathrm{H}), 1.28(\mathrm{~s}, 9 \mathrm{H}) .{ }^{13} \mathrm{C}-\mathrm{NMR}\left(75 \mathrm{MHz}\right.$, DMSO- $\left.d_{6}\right)$ $\delta[\mathrm{ppm}]=149.91,140.09,125.49,124.85,118.76,67.91,34.19,31.12,27.39$. HPLC (Meth. 1): $t_{\mathrm{R}}=12.4 \mathrm{~min}, \mathrm{AUC}=95.2 \%$.

3-(3,5-Di-tert-butylphenyl)-3-hydroxypropanenitrile (3f) White solid, yield: $73 \%$, mp: $136{ }^{\circ} \mathrm{C}$, ${ }^{1} \mathrm{H}-\mathrm{NMR}\left(600 \mathrm{MHz}\right.$, DMSO- $\left.d_{6}\right) \delta[\mathrm{ppm}]=7.31(\mathrm{t}, J=1.7 \mathrm{~Hz}, 1 \mathrm{H}), 7.26(\mathrm{~d}, J=1.5 \mathrm{~Hz}, 2 \mathrm{H}), 5.86$ $(\mathrm{d}, J=4.2 \mathrm{~Hz}, 1 \mathrm{H}), 4.90-4.84(\mathrm{~m}, 1 \mathrm{H}), 2.88(\mathrm{dd}, J=16.7,4.8 \mathrm{~Hz}, 1 \mathrm{H}), 2.79(\mathrm{dd}, J=16.7,6.9 \mathrm{~Hz}$, $1 \mathrm{H}), 1.29(\mathrm{~s}, 18 \mathrm{H}) .{ }^{13} \mathrm{C}-\mathrm{NMR}\left(151 \mathrm{MHz}, \mathrm{DMSO}-d_{6}\right) \delta[\mathrm{ppm}]=150.48,142.79,121.52,120.40$, 119.35, 69.21, 35.02, 31.76, 28.13. EA: calcd for $\mathrm{C}_{17} \mathrm{H}_{25} \mathrm{NO}$ [\%] C 78.72, H 9.71 N 5.40; found [\%] C 78.65; H 9.78; N 5.15 .

3-Hydroxy-3-(6-methoxyquinoline-4-yl)propanenitrile (3g) White solid, yield: $78 \%$, mp: $155^{\circ} \mathrm{C},{ }^{1} \mathrm{H}-\mathrm{NMR}\left(600 \mathrm{MHz}, \mathrm{DMSO}-d_{6}\right) \delta[\mathrm{ppm}]=8.78(\mathrm{~d}, J=4.5 \mathrm{~Hz}, 1 \mathrm{H}), 7.99-7.96(\mathrm{~m}, 1 \mathrm{H})$, $7.65(\mathrm{dd}, J=4.3,0.7 \mathrm{~Hz}, 1 \mathrm{H}), 7.44-7.41(\mathrm{~m}, 2 \mathrm{H}), 6.30(\mathrm{~d}, J=4.4 \mathrm{~Hz}, 1 \mathrm{H}), 5.72(\mathrm{dt}, J=6.3,4.5 \mathrm{~Hz}$, 1H), 3.95 (s, 3H), 3.13 (dd, $J=17.0,4.6 \mathrm{~Hz}, 1 \mathrm{H}), 2.99(\mathrm{dd}, J=17.0,6.4 \mathrm{~Hz}, 1 \mathrm{H}) .{ }^{13} \mathrm{C}-\mathrm{NMR}$ $\left(151 \mathrm{MHz}\right.$, DMSO- $\left.d_{6}\right) \delta[\mathrm{ppm}]=157.84,148.09,146.93,144.25,131.73,126.25,122.02,118.83$, 118.81, 102.28, 64.39, 56.19, 26.86. HPLC (Meth. 1): $t_{\mathrm{R}}=4.47 \mathrm{~min}, \mathrm{AUC} \geq 99 \%$

3-Hydroxy-3-(quinoline-4-yl)propanenitrile (3h) White solid, yield: $70 \%, \mathrm{mp}: 144{ }^{\circ} \mathrm{C}$; ${ }^{1} \mathrm{H}$ NMR (300 MHz, DMSO- $\left.d_{6}\right) \delta[\mathrm{ppm}]=8.95(\mathrm{~d}, J=4.5 \mathrm{~Hz}, 1 \mathrm{H}), 8.22(\mathrm{dd}, J=8.2,1.1 \mathrm{~Hz}, 1 \mathrm{H})$, $8.07(\mathrm{dd}, J=8.5,1 \mathrm{H}), 7.83-7.75(\mathrm{~m}, 1 \mathrm{H}), 7.70(\mathrm{~d}, J=4.5 \mathrm{~Hz}, 1 \mathrm{H}), 7.68-7.62(\mathrm{~m}, 1 \mathrm{H}), 6.34(\mathrm{~d}$, $J=4.3 \mathrm{~Hz}, 1 \mathrm{H}), 5.74(\mathrm{q}, J=5.1 \mathrm{~Hz}, 1 \mathrm{H}), 3.12(\mathrm{dd}, J=16.9,4.6 \mathrm{~Hz}, 1 \mathrm{H}), 2.96(\mathrm{dd}, J=16.9$, $6.4 \mathrm{~Hz}, 1 \mathrm{H}) .{ }^{13} \mathrm{C}-\mathrm{NMR}\left(75 \mathrm{MHz}, \mathrm{DMSO}-d_{6}\right) \delta[\mathrm{ppm}]=150.32,147.81,147.67,129.75,129.21$, $126.75,124.67,123.48,118.18,118.13,63.90,26.74$. HPLC (Meth. 1): $t_{\mathrm{R}}=3.4 \mathrm{~min}, \mathrm{AUC}=$ $99.1 \%$. 
imidomethylester hydrochlorides 4 a-c were previously described by Leven et al. ${ }^{1,2}$ Under nitrogen atmosphere 3d (3.95 g, $16 \mathrm{mmol})$ was dissolved in a mixture of anhyd. DCM (20 mL) and anhyd. THF (5 mL). At $-10{ }^{\circ} \mathrm{C}$ anhyd. methanol $(0.97 \mathrm{~mL}, 24.00 \mathrm{mmol})$ was added and the solution was stirred afterwards for $10 \mathrm{~min}$. Subsequently, $\mathrm{HCl}$ in diethyl ether $(36 \mathrm{~mL})$ was added dropwise to the cooled solution. After further 10 min stirring at $-10^{\circ} \mathrm{C}$ the flask was stored under nitrogen atmosphere at $-20{ }^{\circ} \mathrm{C}$ until the product crystallized as yellow solid. yield: $75 \%$, mp: $230{ }^{\circ} \mathrm{C}$, IR $(\mathrm{KBr}): \tilde{\mathrm{v}}[\mathrm{KBr}]=1648(\mathrm{C}=\mathrm{N})$.

4-Amino-2-((diethylamino)methyl)phenol (5) The known compound 5 was synthesized according to Rodrigues et $a .^{3}$ Brown oil, yield: $83 \%,{ }^{1} \mathrm{H}-\mathrm{NMR}$ (300 MHz, DMSO- $d_{6}$ ) $\delta[\mathrm{ppm}]=10.08(b r-\mathrm{s}, 1 \mathrm{H}), 6.44-6.26(\mathrm{~m}, 3 \mathrm{H}), 4.36(\mathrm{~s}, 2 \mathrm{H}), 3.33(\mathrm{~s}, 4 \mathrm{H}), 1.01(\mathrm{t}, J=7.1 \mathrm{~Hz}, 6 \mathrm{H})$. ${ }^{13} \mathrm{C}-\mathrm{NMR}\left(75 \mathrm{MHz}, \mathrm{DMSO}-d_{6}\right) \delta[\mathrm{ppm}]=148.25,140.45,122.79,115.49,114.85,113.89,55.60$, 45.70, 11.11 .

\section{Biological evaluation}

In vitro activity of the compounds against asexual stages of the P. falciparum lines Pf3D7 (chloroquine sensitive) and PfDd2 (chloroquine resistant) was evaluated with a histidine rich protein 2 (HRP2) enzyme linked immunosorbent assay (ELISA). ${ }^{4,5}$ The $^{\mathrm{IC}_{50}}$ was determined by nonlinear regression analysis of log concentration-response curves using the drc package v0.9.0 of R v2.6.1. ${ }^{6}$ Evaluation of the cytotoxicity of the compounds against HepG2, HELA and HEK293 cells were evaluated based on a neutral red assay. ${ }^{7,8}$ Briefly, human cells were seeded to a 96 well plate in complete culture medium. On the following day, serial dilutions of the compounds were added. After one day of incubation, cytotoxicity was evaluated by the addition of neutral red, subsequent lysis of cells and the measurement of absorbance in a plate reader. 
Mouse experiments were conducted as published. ${ }^{9}$ The animal experiments performed at the Swiss Tropical and Public Health Institute (Swiss TPH) were approved by the Swiss Cantonal Authorities (Permission No. 1731). In cases when parasitemia reduction on day 4 was smaller than $40 \%$, mice were euthanized on that day in order to prevent death otherwise occurring due to the high parasitemia. The survival of the animals is monitored up to 30 days. Mice surviving for 30 days are checked for parasitemia by microscopy and subsequently euthanized.

\section{Cellular heme fractionation assay}

Details of this protocol have previously been described. ${ }^{10}$ Briefly, sorbitol-synchronized early ringstage PfNF54 parasites ( $<3 \mathrm{~h}$ post-invasion) were incubated with the test drugs at various multiples of their $\mathrm{IC}_{50}$ values, and a no-drug control included. After $32 \mathrm{~h}$, late trophozoites/early schizonts were harvested by lysis of the RBCs with $0.05 \%$ saponin followed by multiple washes with $1 \times$ PBS $(\mathrm{pH} 7.5)$ to remove traces of the RBC hemoglobin and the pellet suspended in 1xPBS ( $\mathrm{pH} 7.5)$. An aliquot of the trophozoite suspension was used to quantify, using flow cytometry, the total number of trophozoite cells isolated.

The contents of the remaining trophozoite pellet were then released by hypotonic lysis and sonication. Following centrifugation, treatment with HEPES buffer ( $\mathrm{pH} 7.4)$, SDS, pyridine and $\mathrm{NaOH}$, the fractions corresponding to digested hemoglobin, "free" heme and hemozoin were carefully recovered. The UV-visible spectrum of each heme fraction as an Fe(III)heme-pyridine complex was measured using a multiwell plate reader (Spectramax 340PC; Molecular Devices). The total amount of each heme species was quantified using a heme standard curve whereby the mass of each heme Fe species per trophozoite was calculated by dividing the total amount of each heme species by the corresponding number of parasites in that fraction as determined by flow cytometry. Statistical comparisons and analyses for trends were made on GraphPad Prism version 8 using Students' t-test (GraphPad Software Inc., La Jolla, CA, USA).

\section{In vitro selection of resistance}

Three independent flasks with $1 \times 10^{9}$ Dd2-B2 or Pf_Pol $\delta$ parasites were exposed to $3 \times$ their $\mathrm{IC}_{50}$ as defined using standard $72 \mathrm{~h}$ drug-response assays with asynchronous asexual blood stage parasites. ${ }^{11}$ Briefly, culture parasitaemias were monitored and drug media was changed daily until 
sensitive parasites were cleared. Afterwards, drug media was refreshed every other day and culture volume was reduced by $25 \%$ every week. Once recrudescent parasites were observed, the $\mathrm{IC}_{50}$ shift was confirmed in $72 \mathrm{~h}$ drug-response assays. Cultures with less than a 2 -fold $\mathrm{IC}_{50}$ increase were subjected to increasing concentrations of compound with the aim of exerting higher levels of resistance that would likely drive genetic changes. Resistant cultures were cloned by limiting dilution to isolate genetically homogenous lines for further characterization. For this, one parasitized RBC was seeded every other well in a 96-well plate for a total of 48 parasitized RBC per flask. Fresh media and compound were supplied once a week for three weeks or until resistant parasites were detected at a minimum of $0.2 \%$ parasitemia in a BD Biosciences Accuri C6 flow cytometer. Resistant clonal lines were expanded to $50 \mathrm{~mL}$ of culture to profile new $\mathrm{IC}_{50}$ values and to extract DNA using the QiAmp DNA Blood Mini kit (Qiagen).

Whole-genome sequencing of the clones FL1-D6, FL2-C4 and the Pf_Pol $\delta$ parent was performed using the Illumina Nextera DNA Flex library protocol and NextSeq 550 sequencing platform to obtain $150 \mathrm{bp}$ paired end reads. The sequence reads were aligned to the $P$. falciparum 3D7 genome (PlasmoDB version 36) using BWA (Burrow-Wheeler Alignment). PCR duplicates and unmapped reads were filtered out using Samtools and Picard. The reads were realigned around indels using GATK RealignerTargetCreator and base quality scores were recalibrated using GATK TableRecalibration. GATK HaplotypeCaller (version 4.1.7) was used to identify of all possible single nucleotide variants (SNVs)in clones which were filtered based on quality scores (variant quality as function of depth QD $>1.5$, mapping quality $>40$, min base quality score $>18$ ), read depth (depth of read $>5$ ) to obtain high quality SNPs that were annotated using snpEFF. IGV was used to visually verify the SNP's presence in the clones. BicSeq was used to discover copy number variants (CNVs) against the Dd2 Pf_Pol $\delta$ parent as well as the 3D7 reference line. pfmdr1 copy numbers were measured by TaqMan-based qPCR using the SsoAdvanced universal SYBR green supermix (Bio-Rad) and the Applied Biosystem QuantStudio 3 Real-Time PCR system (ThermoFisher Scientific). As a reference, the single copy $\beta$-tubulin (PF3D7_1008700) gene was used. Amplifications were executed in $20 \mathrm{uL}$ total reaction mixtures and loaded in triplicate. 


\section{Supplementary tables}

Supplementary Table 1. Whole-genome sequence metrics from Illumina NextSeq (150bp paired end reads) for the two $P$. falciparum compound 1 resistant clones and the sensitive $P f \_$Pol $\delta$ parent.

\begin{tabular}{|c|c|c|c|c|}
\hline & Samples & FL1-D6 & FL2-C4 & 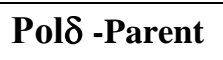 \\
\hline & Total Reads & $8,596,778$ & $7,762,394$ & $7,666,054$ \\
\hline & \# mapped reads & $8,523,673$ & $7,699,563$ & $7,607,313$ \\
\hline & Mean coverage & 47 & 42 & 42 \\
\hline อั & SD & 122 & 108 & 105 \\
\hline & $\mathbf{1 X}$ & 97.9 & 97.7 & 97.7 \\
\hline$\stackrel{\square}{\underline{Z}}$ & $5 \mathbf{X}$ & 96.5 & 96.1 & 96.1 \\
\hline$\stackrel{x}{\wedge}$ & $10 \mathrm{X}$ & 94.8 & 94.0 & 94.0 \\
\hline 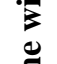 & 30X & 81.5 & 76.4 & 77.1 \\
\hline 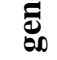 & mean mapping quality (Phred) & 53.0 & 53.0 & 53.0 \\
\hline $\begin{array}{l}\ddot{0} \\
\therefore 0\end{array}$ & p25/median/p75 insert size (bp) & $200 / 255 / 316$ & $200 / 256 / 317$ & $215 / 274 / 336$ \\
\hline
\end{tabular}


Supplementary Table 2. List of non-synonymous mutations identified in the two $P$. falciparum compound 1 resistant clones when compared to the sensitive $P f$ Pol $\delta$ parent. pfmdr2 (PF3D7_1447900) is identified in both clones FL1-D6 and FL2-C4.

\begin{tabular}{|c|c|c|c|c|c|c|c|}
\hline Chr & Position & Ref & Alt & $\begin{array}{l}\text { Mutation } \\
\text { in }\end{array}$ & $\begin{array}{l}\text { Amino } \\
\text { acid } \\
\text { change }\end{array}$ & Gene & Description \\
\hline 4 & 342718 & G & A & FL1-D6 & S446F & PF3D7_0406500 & $\begin{array}{l}\text { NYN domain-containing protein, } \\
\text { putative }\end{array}$ \\
\hline 6 & 600189 & G & A & FL1-D6 & S110F & PF3D7_0614300 & $\begin{array}{l}\text { major facilitator superfamily- } \\
\text { related transporter, putative }\end{array}$ \\
\hline 8 & 1265360 & G & $\mathrm{T}$ & FL1-D6 & $\mathrm{H} 447 \mathrm{~N}$ & PF3D7_0829500 & $\begin{array}{c}\text { conserved Plasmodium protein, } \\
\text { unknown function }\end{array}$ \\
\hline 12 & 1212941 & G & A & FL1-D6 & R336K & PF3D7_1229500 & $\begin{array}{l}\text { T-complex protein } 1 \text { subunit } \\
\text { gamma }\end{array}$ \\
\hline 13 & 1230446 & G & $\mathrm{T}$ & FL1-D6 & $\mathrm{T} 1201 \mathrm{~N}$ & PF3D7_1329100 & myosin $\mathrm{F}$, putative \\
\hline 4 & 348612 & G & $\mathrm{T}$ & FL2-C4 & D189Y & PF3D7_0406700 & $\begin{array}{l}\text { conserved Plasmodium protein, } \\
\text { unknown function }\end{array}$ \\
\hline 7 & 797613 & A & $\mathrm{C}$ & FL2-C4 & F2330C & PF3D7_0718100 & $\begin{array}{l}\text { exported serine/threonine protein } \\
\text { kinase }\end{array}$ \\
\hline 8 & 1212812 & $\mathrm{C}$ & $\mathrm{T}$ & FL2-C4 & R876K & PF3D7_0828100 & $\begin{array}{c}\text { conserved Plasmodium protein, } \\
\text { unknown function }\end{array}$ \\
\hline 11 & 2003182 & $\mathrm{C}$ & A & FL2-C4 & Q672K & PF3D7_1149600 & DnaJ protein, putative \\
\hline 12 & 733462 & $\mathrm{~T}$ & G & FL2-C4 & K386Q & PF3D7_1218600 & arginine--tRNA ligase \\
\hline 12 & 1465399 & G & $\mathrm{T}$ & FL2-C4 & S725Y & PF3D7_1235200 & $\begin{array}{c}\text { V-type } \mathrm{K}+\text {-independent } \mathrm{H}+- \\
\text { translocating inorganic } \\
\text { pyrophosphatase }\end{array}$ \\
\hline
\end{tabular}




\begin{tabular}{|c|c|c|c|c|c|c|c|}
\hline 12 & 1501303 & $\mathrm{C}$ & $\mathrm{T}$ & FL2-C4 & E37K & PF3D7_1235900 & $\begin{array}{c}\text { pre-mRNA-splicing factor SYF1, } \\
\text { putative }\end{array}$ \\
\hline 14 & 1956324 & G & A & $\begin{array}{c}\text { FL1-D6, } \\
\text { FL2-C4 }\end{array}$ & S451F & PF3D7_1447900 & $\begin{array}{c}\text { multidrug resistance protein 2 } \\
\text { (mdr2) }\end{array}$ \\
\hline
\end{tabular}

Supplementary Table 3. List of genes and copy numbers in respective compound 1 treated clones FL1D6, FL2-C4 and sensitive $P f$ Pol $\delta$ parent, compared to 3D7 in the $81 \mathrm{~kb}$ amplified segment on chromosome 5. 3D7 contains 1 copy. pfmdr1 (PF3D7_0523000) is identified within this $81 \mathrm{~kb}$ amplified segment.

\begin{tabular}{|l|l|l|l|l|}
\hline Gene ID & Annotation & FL1-D6 & FL2-C4 & $\begin{array}{l}\text { Pol } \delta \\
\text { Parent }\end{array}$ \\
\hline PF3D7_0521900 & conserved Plasmodium protein, unknown function & 4.7 & 4.6 & 2 \\
\hline PF3D7_0522000 & conserved Plasmodium protein, unknown function & 4.7 & 4.6 & 2 \\
\hline PF3D7_0522100 & conserved Plasmodium protein, unknown function & 4.7 & 4.6 & 2 \\
\hline PF3D7_0522200 & $\begin{array}{l}\text { transcription initiation factor TFIID subunit 10, } \\
\text { putative }\end{array}$ & 4.7 & 4.6 & 2 \\
\hline PF3D7_0522300 & 18S rRNA (guanine-N(7))-methyltransferase, putative & 4.7 & 4.6 & 2 \\
\hline PF3D7_0522400 & conserved Plasmodium protein, unknown function & 4.7 & 4.6 & 2 \\
\hline PF3D7_0522500 & 50S ribosomal protein L17, apicoplast, putative & 4.7 & 4.6 & 2 \\
\hline PF3D7_0522600 & inner membrane complex protein & 4.7 & 4.6 & 2 \\
\hline PF3D7_0522700 & iron-sulfur assembly protein & 4.7 & 4.6 & 2 \\
\hline PF3D7_0522800 & pre-mRNA-splicing factor BUD31, putative & 4.7 & 4.6 & 2 \\
\hline PF3D7_0522900 & zinc finger protein, putative & 4.7 & 2.6 \\
\hline PF3D7_0523100 & putative & 4.7 & 2 \\
\hline & multidrug resistance protein 1 & 4.6 & 2 \\
\hline & & & & \\
\hline
\end{tabular}




\section{Supplementary figure}

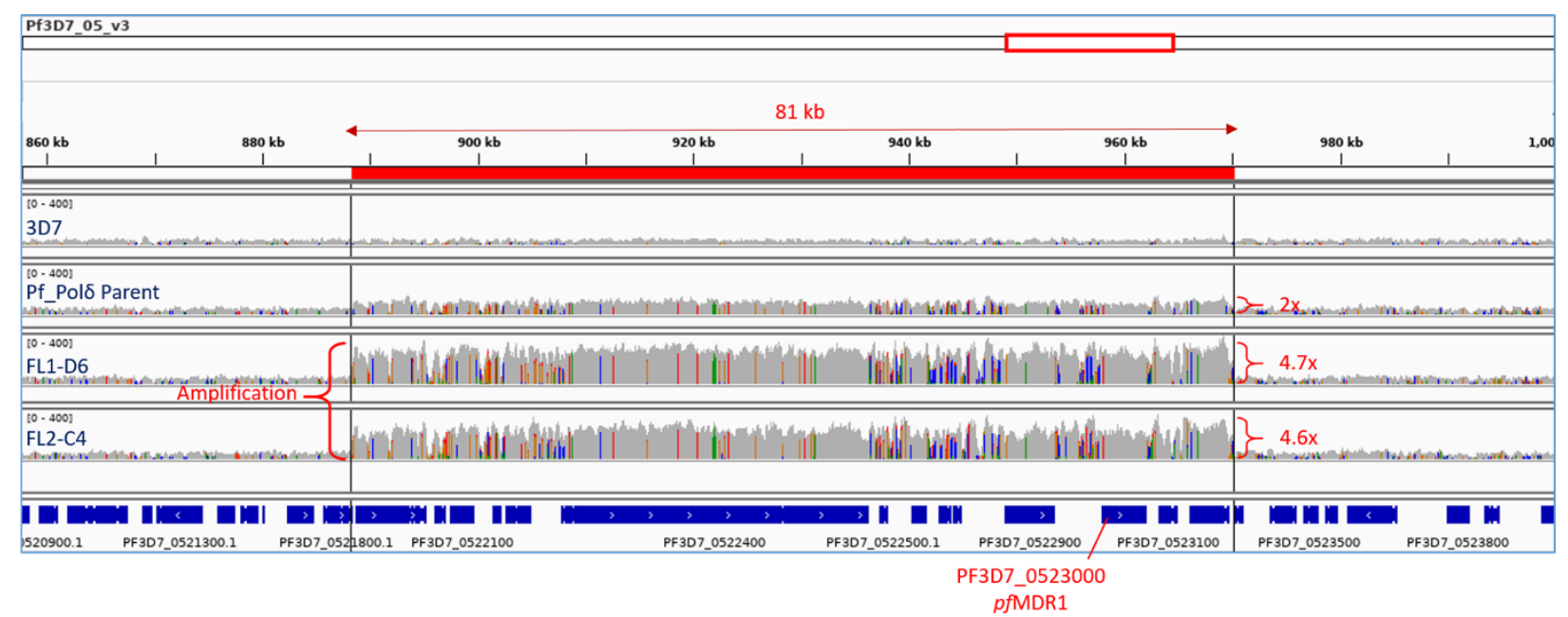

Supplementary Figure 1. Snapshot from Integrated Genomics Viewer showing $81 \mathrm{~kb}$ amplified segment of chromosome 5 in sensitive $P f$ Pol $\delta$ parent and compound 1 treated clones FL1-D6, FL2-C4 compared against 3D7. $P f \_$Pol $\delta$ parent has a naturally occurring amplification of 2 copies against 3D7. Compound 1 treated clones FL1-D6 and FL2-C4 show significant amplification of 4.7 and 4.6 copies respectively. 
7. ${ }^{1} \mathrm{H}-,{ }^{13} \mathrm{C}-$ Spectra and HPLC chromatograms of target compounds

$\underline{N^{\prime} \text {-(4-Fluorobenzyl)-3-hydroxy-3-(phenanthrene-9-yl)propanimidamide Hydrochloride (6) }}$

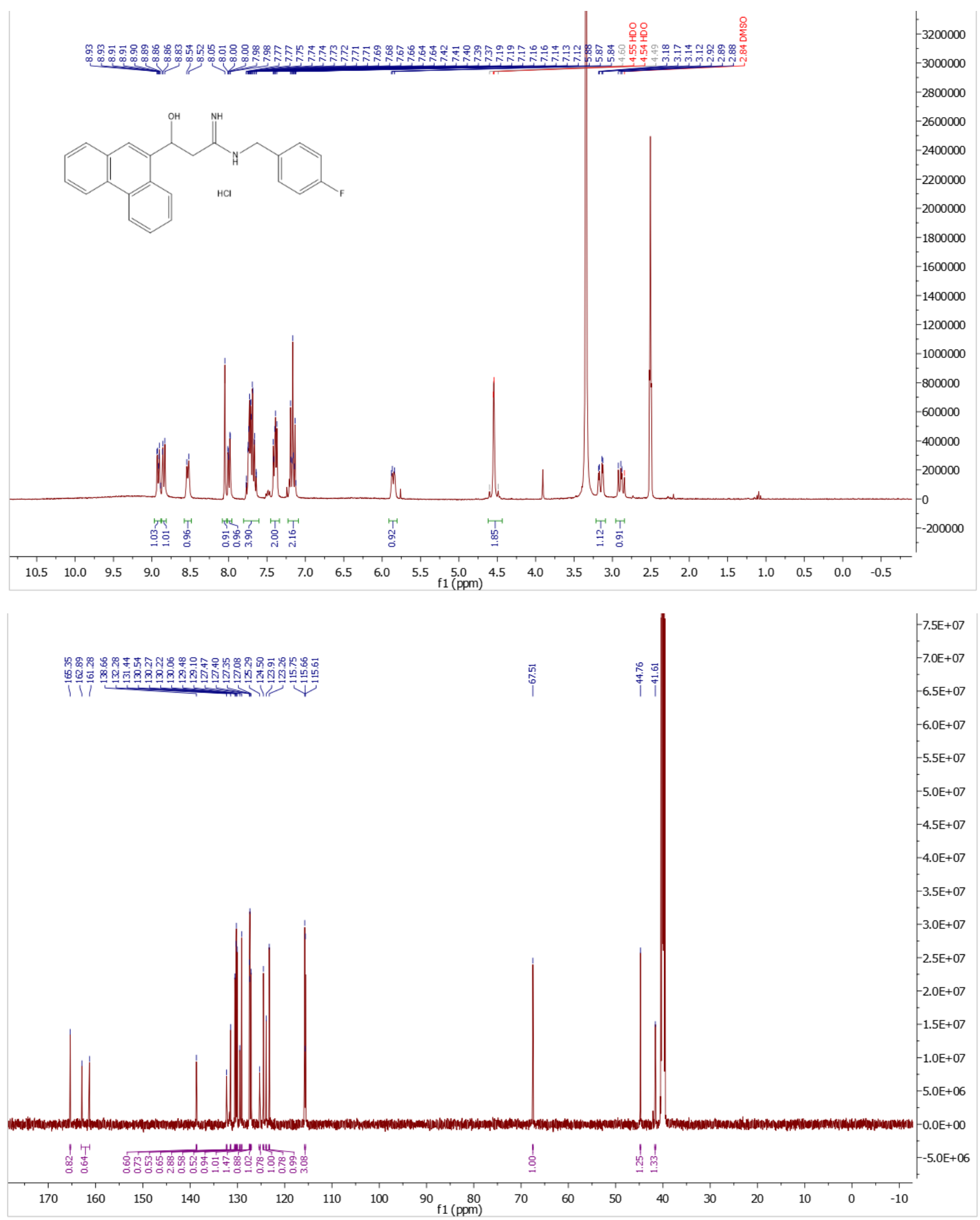

S11 


\section{3-Hydroxy-3-(phenanthrene-9-yl)- $N^{\prime}$-phenethylimidamide Hydrochloride (7)}
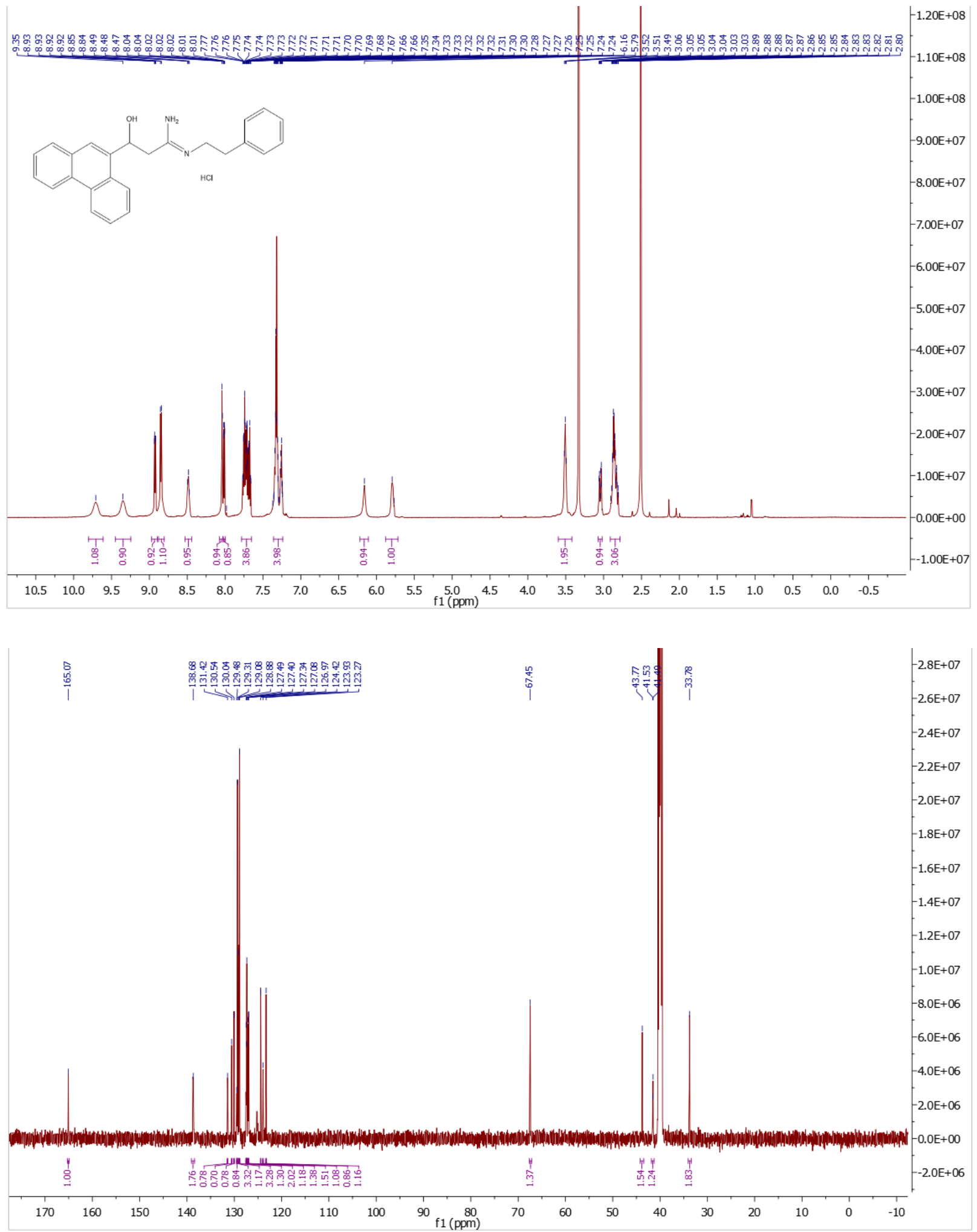


\section{$\underline{N^{\prime} \text {-Benzyl-3-hydroxy-3-(phenanthrene-9-yl)propanimidamide Hydrochloride (8) }}$}
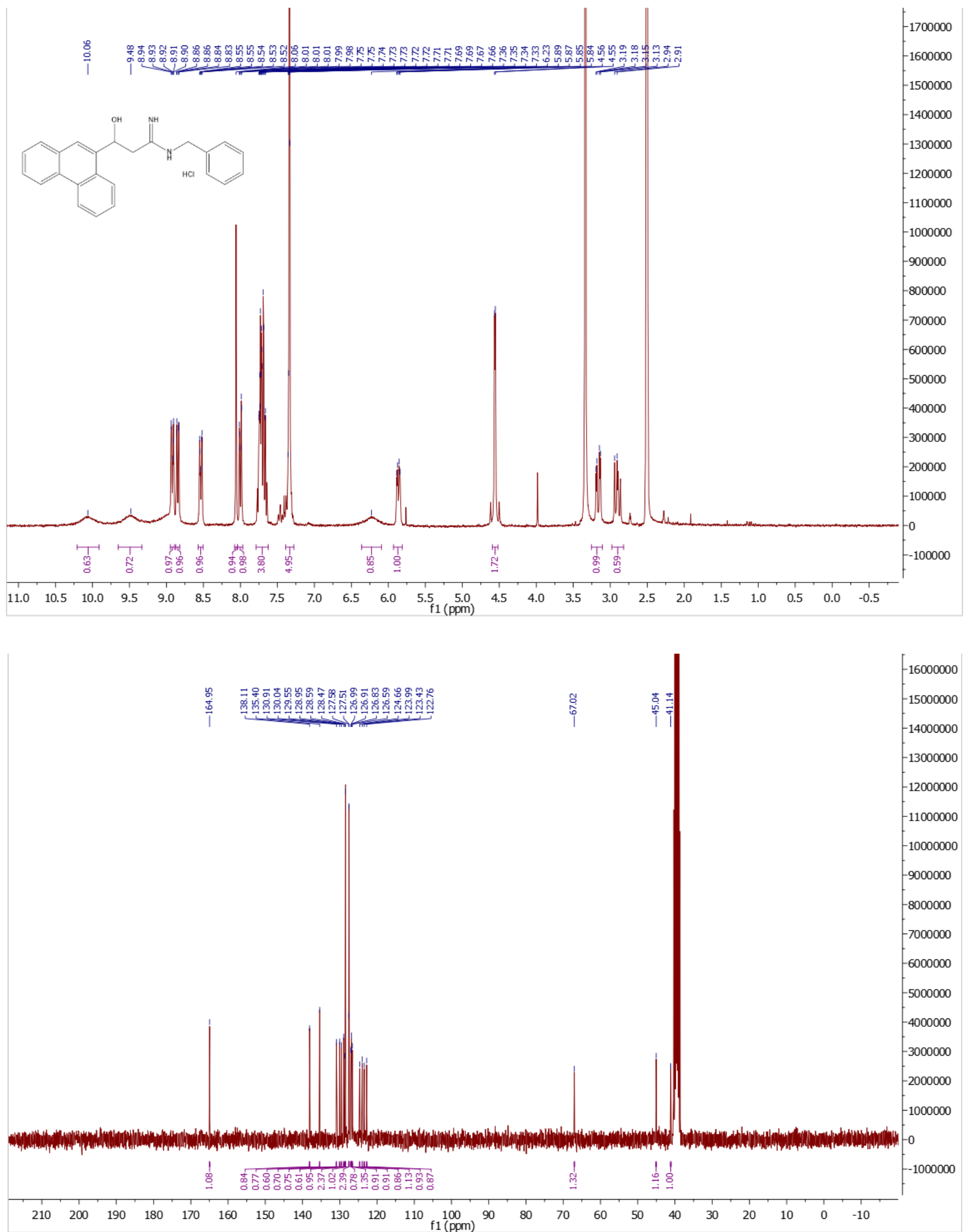


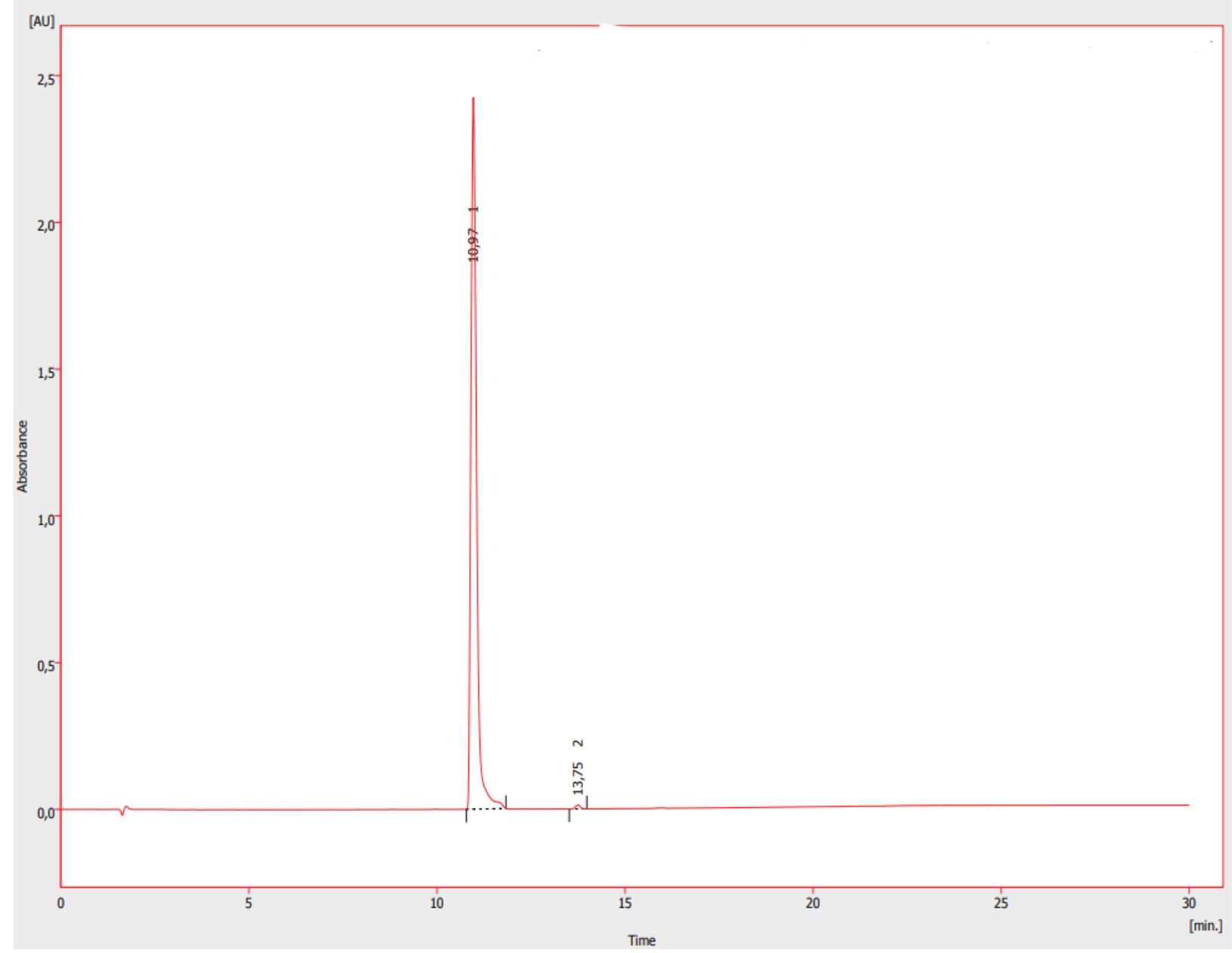

\begin{tabular}{|c|r|r|r|r|r|r|r|r|r|}
\hline & $\begin{array}{c}\text { Reten. Time } \\
{[\mathrm{min}]}\end{array}$ & $\begin{array}{c}\text { Start Time } \\
{[\mathrm{min}]}\end{array}$ & $\begin{array}{c}\text { End Time } \\
{[\mathrm{min}]}\end{array}$ & $\begin{array}{c}\text { Start Value } \\
{[\mathrm{mAU}]}\end{array}$ & $\begin{array}{c}\text { End Value } \\
{[\mathrm{mAU}]}\end{array}$ & $\begin{array}{c}\text { Area } \\
{[\mathrm{mAU} . \mathrm{s}]}\end{array}$ & $\begin{array}{c}\text { Height } \\
{[\mathrm{mAU}]}\end{array}$ & $\begin{array}{c}\text { Area } \\
{[\%]}\end{array}$ & $\begin{array}{c}\text { Height } \\
{[\%]}\end{array}$ \\
\hline 1 & 10,967 & 10,783 & 11,833 & 0,393 & 3,036 & 25149,537 & 2424,135 & 99,6 & 99,5 \\
\hline 2 & 13,750 & 13,517 & 13,983 & 1,645 & 2,080 & 111,701 & 12,690 & 0,4 & 0,5 \\
\hline & Total & & & & & 25261,239 & 2436,824 & 100,0 & 100,0 \\
\hline
\end{tabular}


(9)
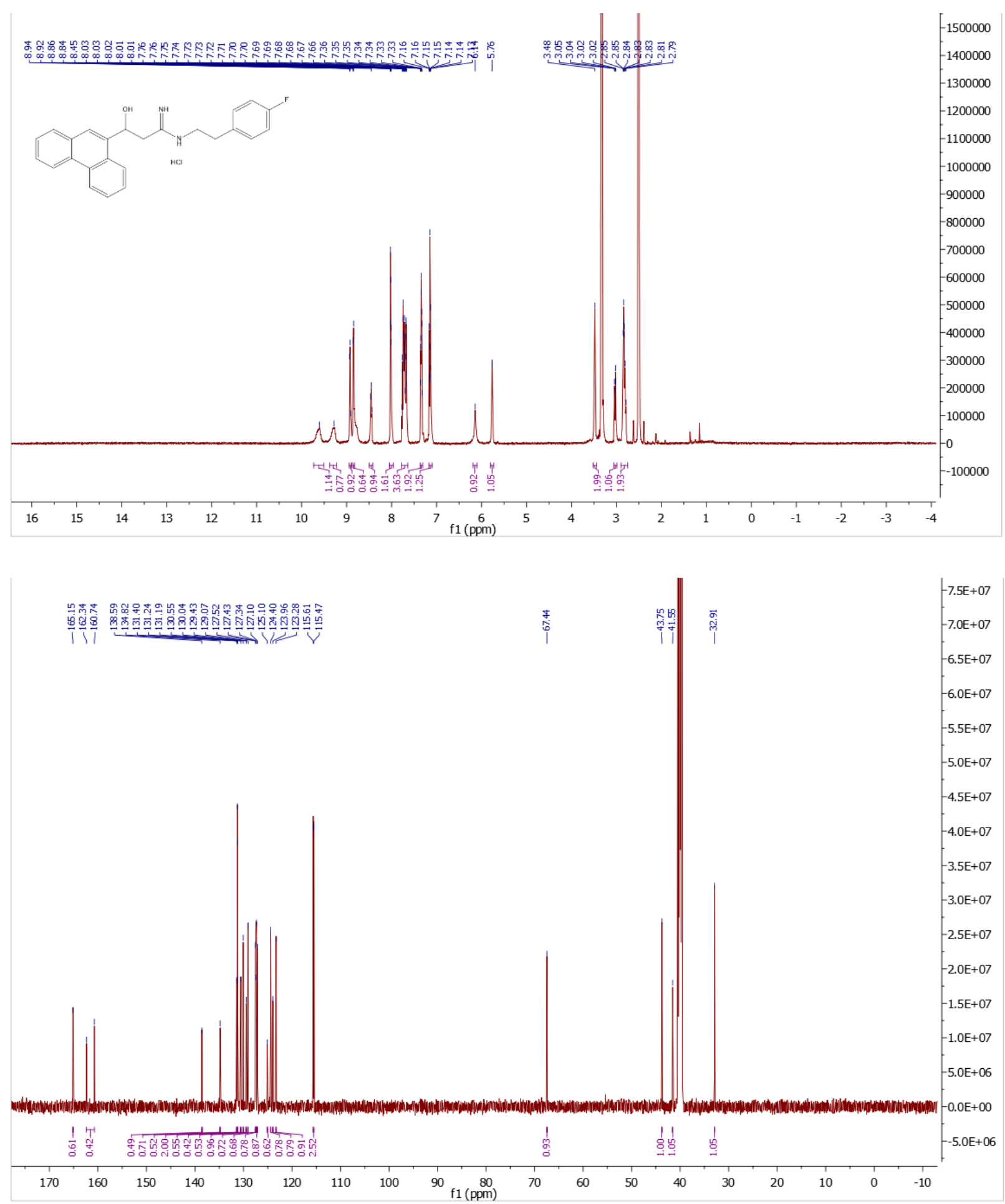
$\underline{\text { (Z)-3-Hydroxy-3-(phenanthrene-9-yl)- } N^{\prime}-(2-(\text { pyridin-2-yl)ethyl)propanimidamide }}$

Hydrochloride (10)
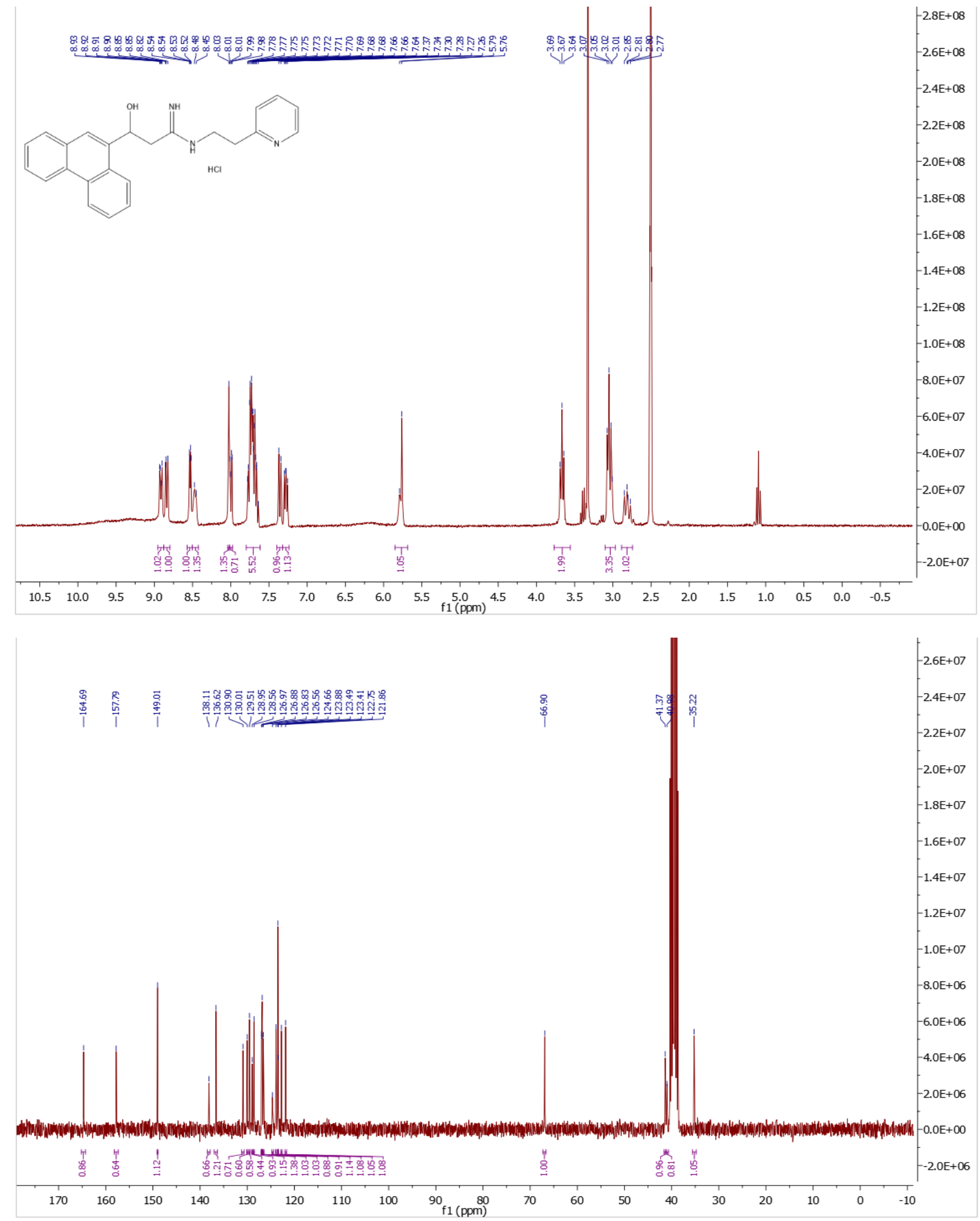

S16 


\section{Hydrochloride (11)}

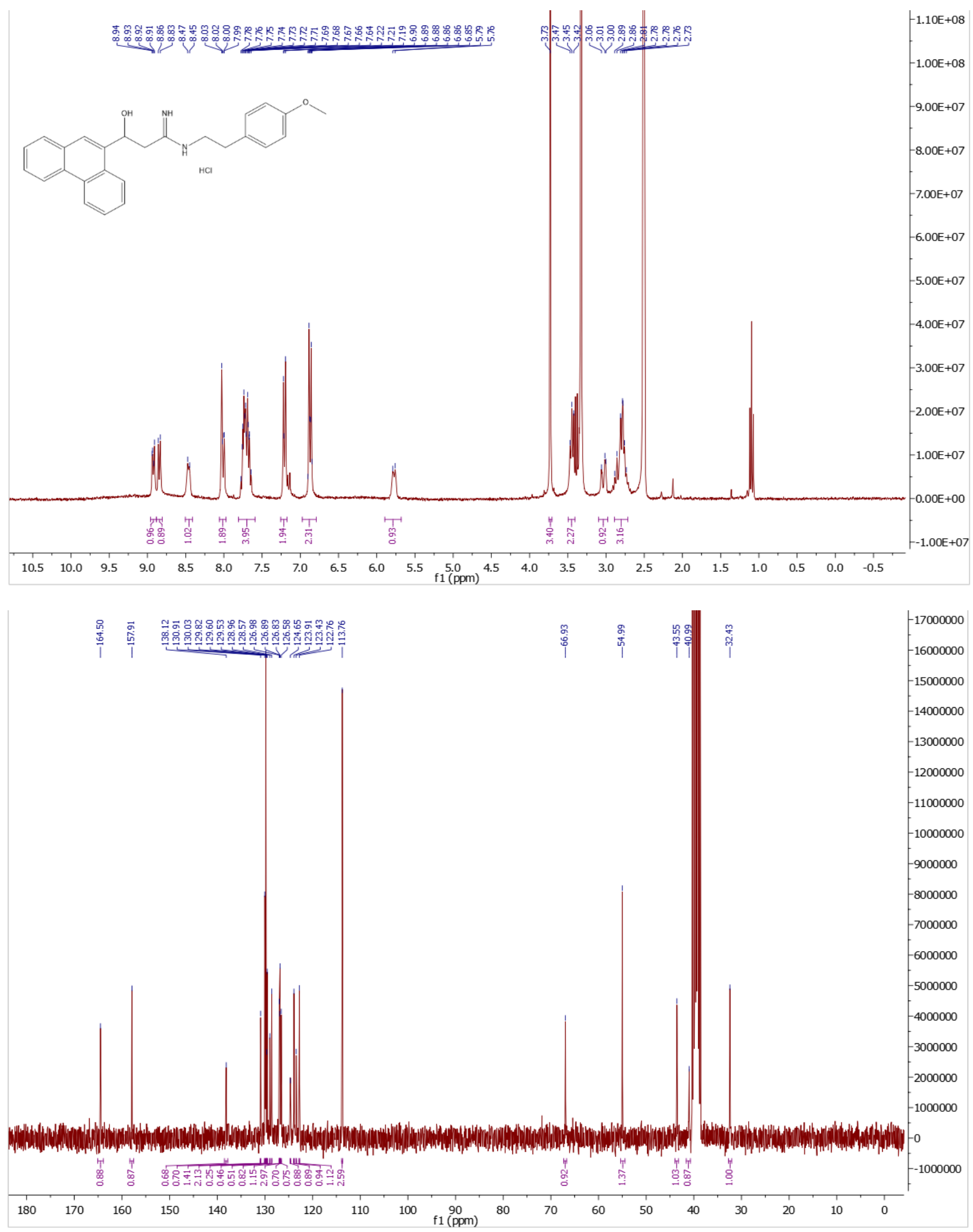

S17 


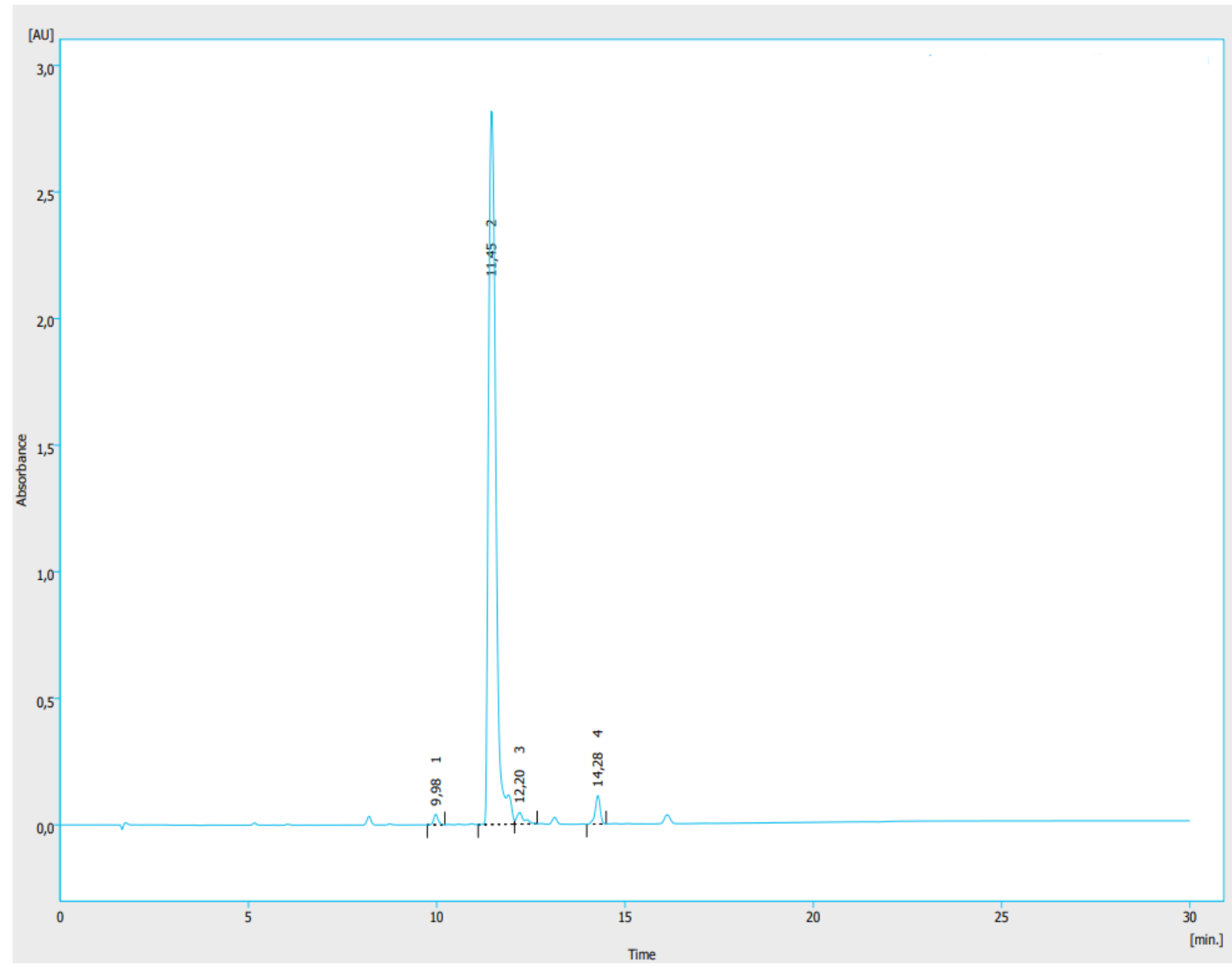

\begin{tabular}{|r|r|r|r|r|r|r|r|r|r|r|}
\hline & $\begin{array}{c}\text { Reten. Time } \\
{[\mathrm{min}]}\end{array}$ & $\begin{array}{c}\text { Start Time } \\
{[\mathrm{min}]}\end{array}$ & $\begin{array}{c}\text { End Time } \\
{[\mathrm{min}]}\end{array}$ & $\begin{array}{c}\text { Start Value } \\
{[\mathrm{mAU}]}\end{array}$ & $\begin{array}{c}\text { End Value } \\
{[\mathrm{mAU}]}\end{array}$ & $\begin{array}{c}\text { Area } \\
{[\mathrm{mAU} . \mathrm{s}]}\end{array}$ & $\begin{array}{c}\text { Height } \\
{[\mathrm{mAU}]}\end{array}$ & $\begin{array}{c}\text { Area } \\
{[\%]}\end{array}$ & $\begin{array}{c}\text { Height } \\
{[\%]}\end{array}$ \\
\hline 1 & 9,983 & 9,750 & 10,217 & 0,161 & 0,836 & 339,068 & 41,275 & 0,8 \\
\hline 2 & 11,450 & 11,100 & 12,067 & 0,958 & 3,083 & 38317,471 & 2817,352 & 95,1 & 1,4 \\
\hline 3 & 12,200 & 12,067 & 12,667 & 3,083 & 4,402 & 629,712 & 46,171 & 1,6 & 1,5 \\
\hline 4 & 14,283 & 13,983 & 14,500 & 3,175 & 3,911 & 1020,854 & 112,450 & 2,5 \\
\hline & Total & & & & 40307,105 & 3017,248 & 100,0 \\
\hline
\end{tabular}


$\underline{\text { (Z)-3-(1,3-Difluoro-6-(trifluoromethyl)phenanthrene-9-yl)- } N^{\prime} \text {-(4-fluorophenethyl)-3 }}$

hydroxpropanimidamide Hydrochloride (12)
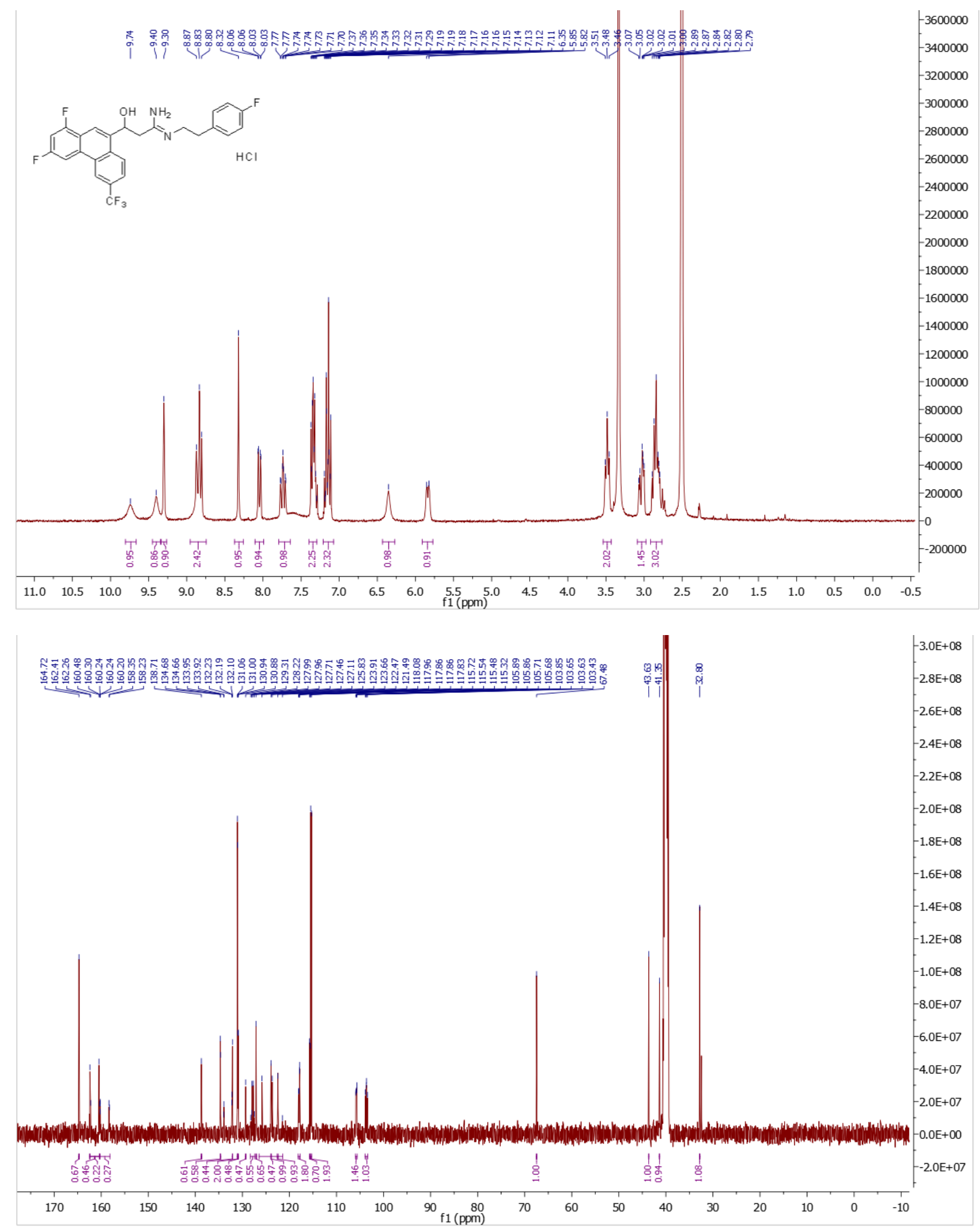

S19 


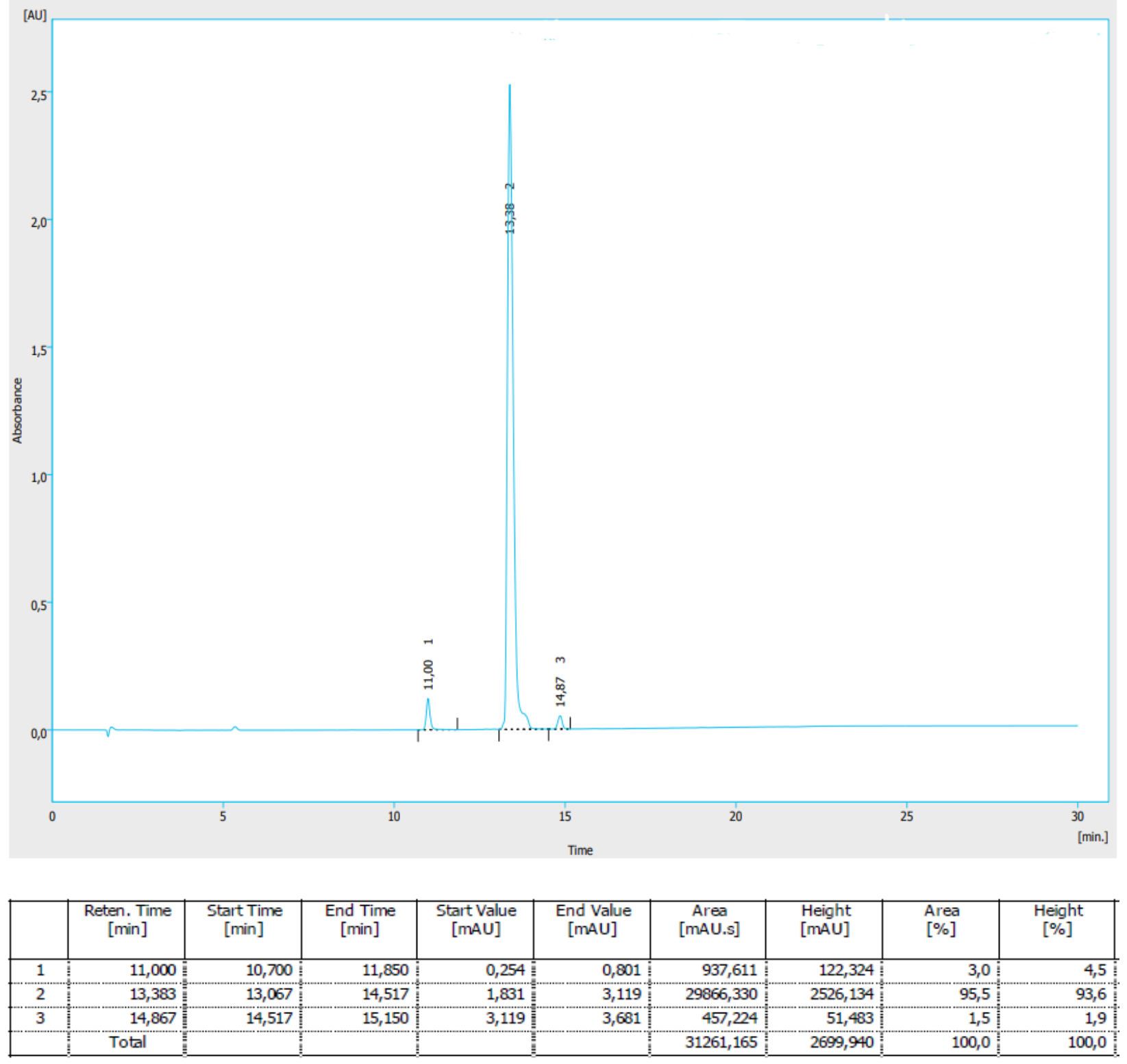


3-(1,3-Dichloro-6-(trifluoromethyl)phenanthren-9-yl)- $N^{\prime}$-(4-fluorophenethyl)-3-hydroxypropanimidamide Hydrochloride (13)
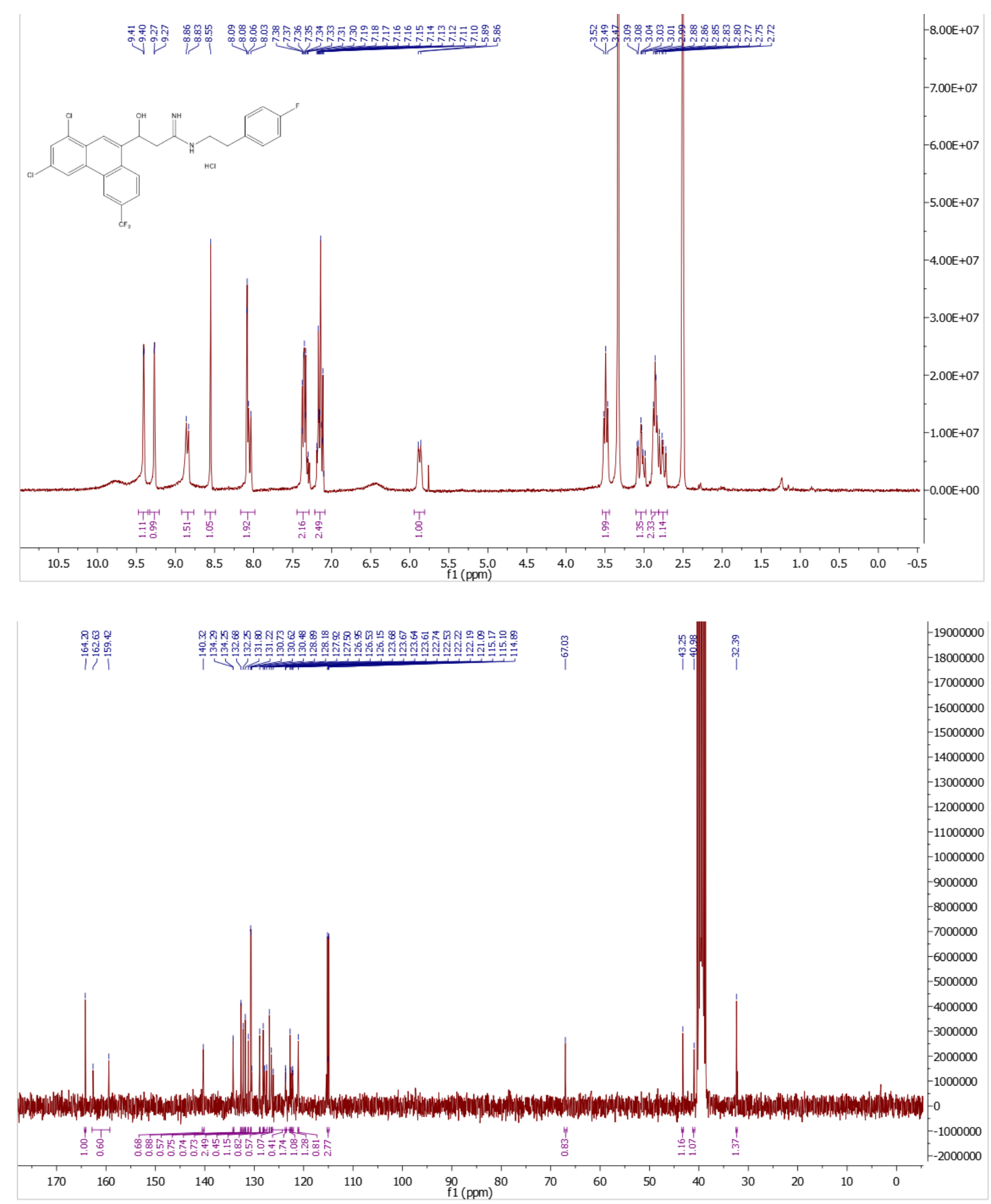
$\underline{\text { (Z)-3-(4-(tert-Butyl)phenyl)- } N^{\prime} \text {-(4-fluorophenyl)-3-hydroxypropanimidamide (14) }}$
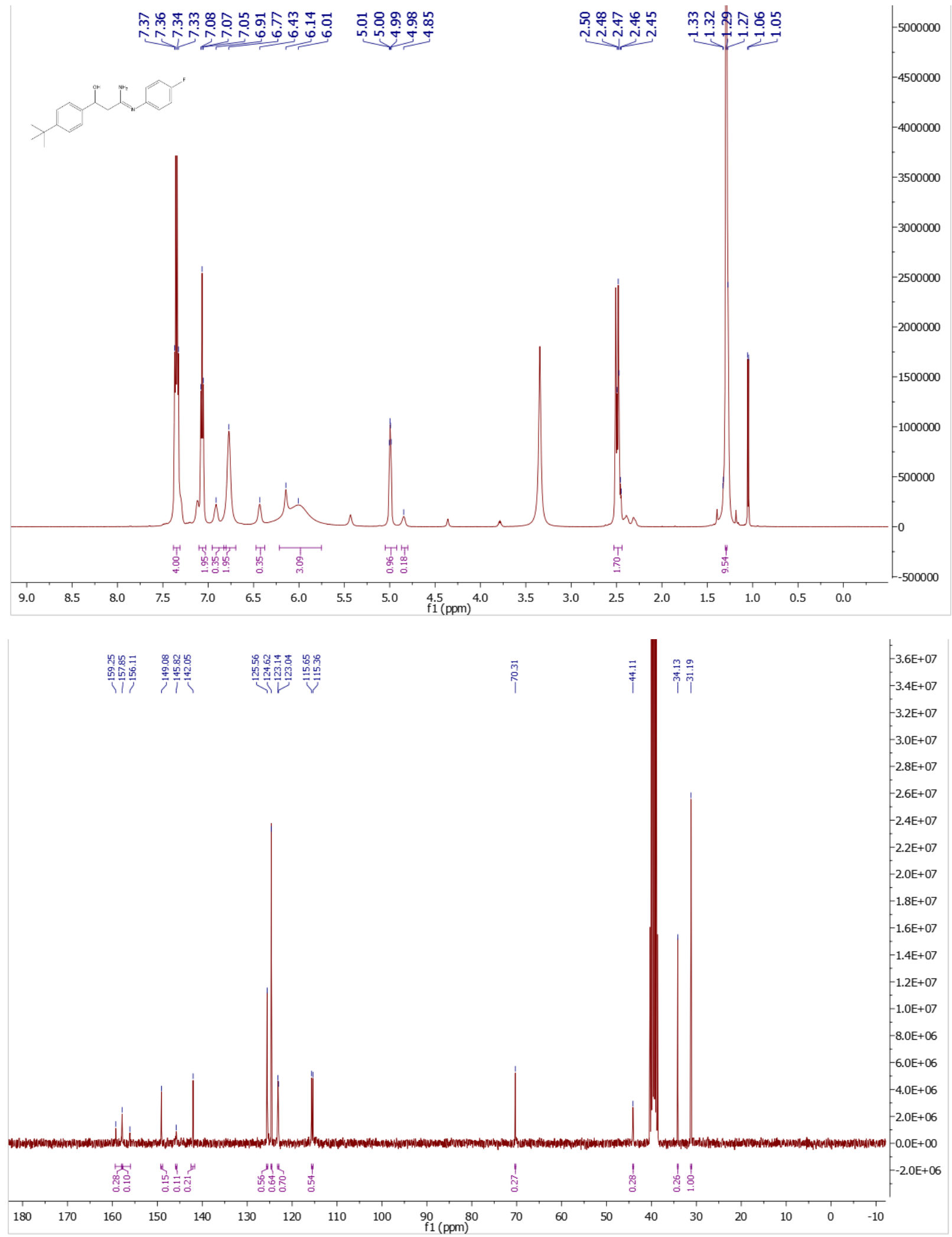


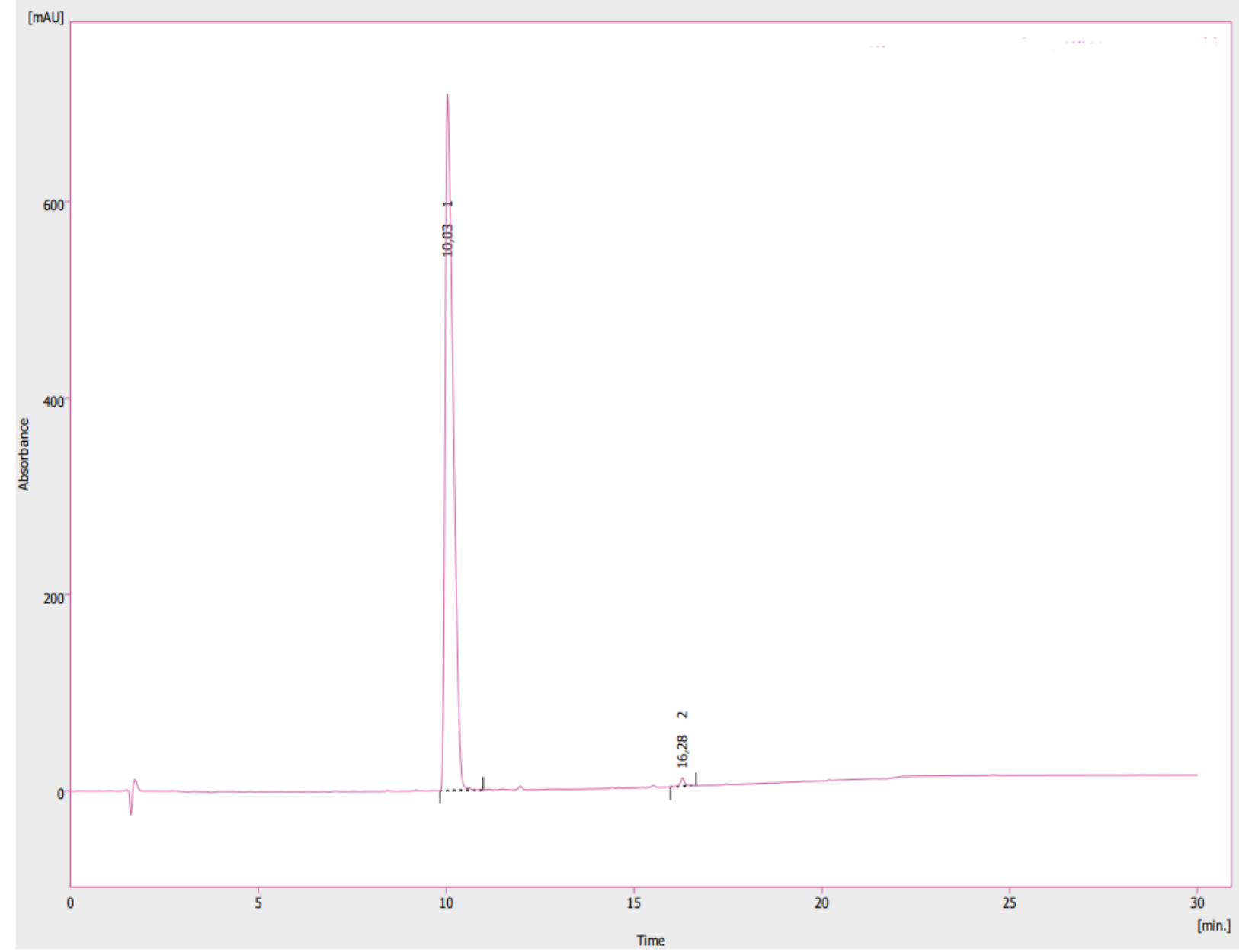

\begin{tabular}{|c|c|c|c|c|c|c|c|c|c|}
\hline & $\begin{array}{c}\text { Reten. Time } \\
\text { [min] }\end{array}$ & $\begin{array}{l}\text { Start Time } \\
\text { [min] }\end{array}$ & $\begin{array}{c}\text { End Time } \\
\text { [min] }\end{array}$ & $\begin{array}{c}\text { Start Value } \\
\text { [mAU] }\end{array}$ & $\begin{array}{c}\text { End Value } \\
\text { [mAU] }\end{array}$ & $\begin{array}{c}\text { Area } \\
\text { [mAU.s] }\end{array}$ & $\begin{array}{l}\text { Height } \\
\text { [mAU] }\end{array}$ & $\begin{array}{l}\text { Area } \\
{[\%]}\end{array}$ & $\begin{array}{l}\text { Height } \\
{[\%]}\end{array}$ \\
\hline 1 & 10,033 & 9,833 & 10,983 & 0,185 & 0,767 & 10593,136 & 708,924 & 99,3 & 98,8 \\
\hline 2 & 16,283 & 15,967 & 16,650 & 4,015 & 5,436 & 70,783 & 8,799 & 0,7 & 1,2 \\
\hline & Total & & & & & 10663,918 & 717,723 & 100,0 & 100,0 \\
\hline
\end{tabular}



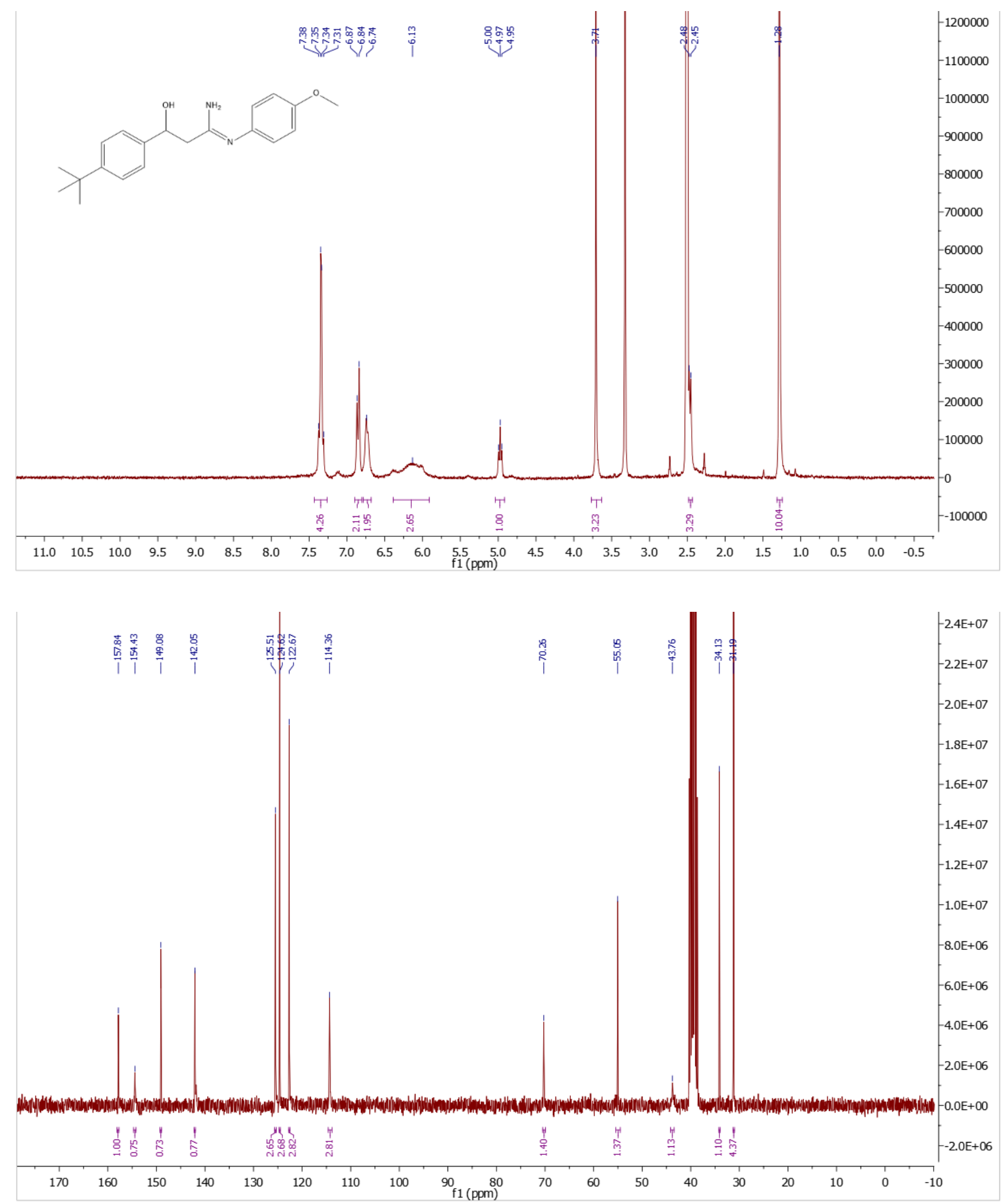


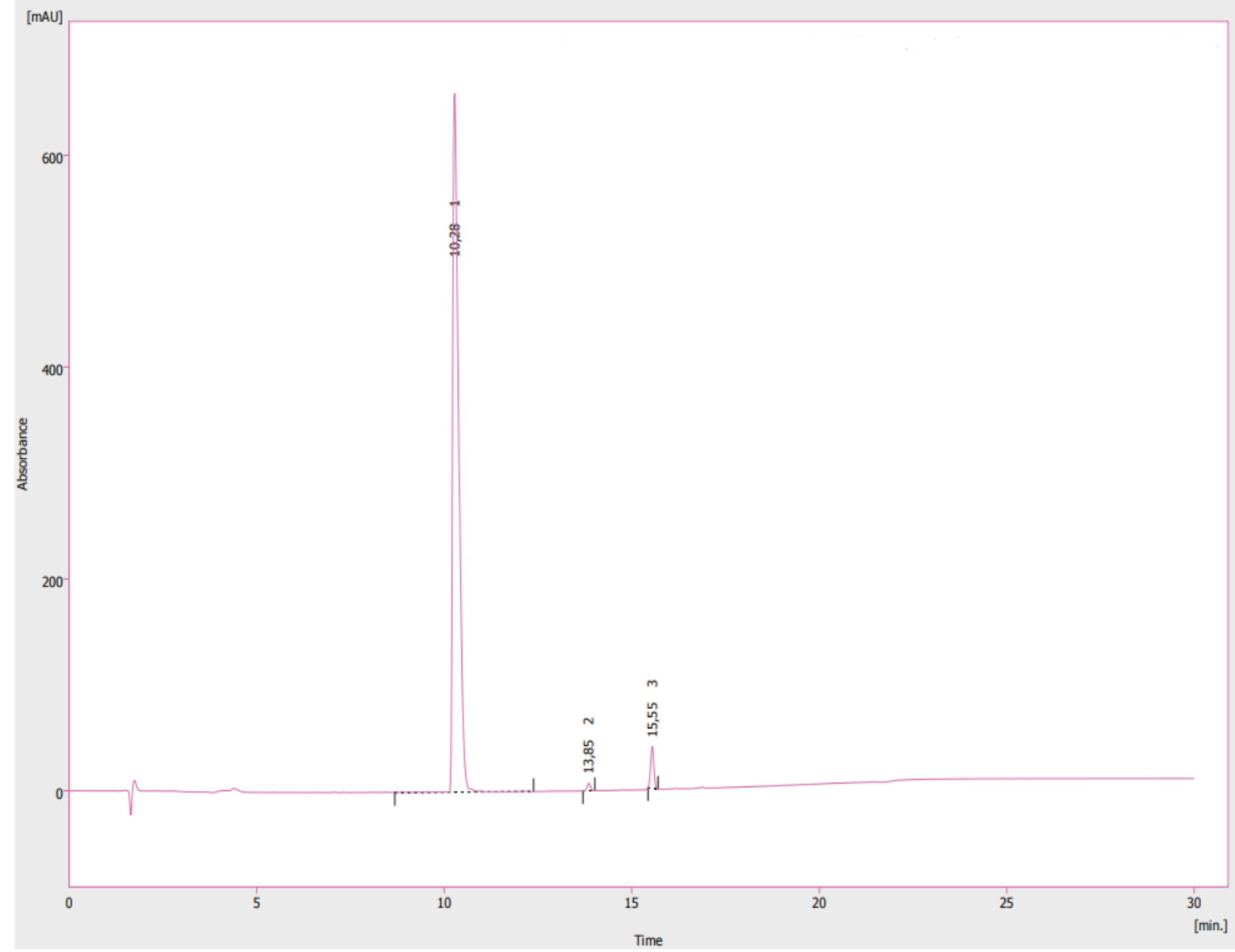

\begin{tabular}{|c|c|c|c|c|c|c|c|c|c|}
\hline & $\begin{array}{l}\text { Reten. Time } \\
{[\mathrm{min}]}\end{array}$ & $\begin{array}{c}\text { Start Time } \\
{[\mathrm{min}]}\end{array}$ & $\begin{array}{l}\text { End Time } \\
\text { [min] }\end{array}$ & $\begin{array}{c}\text { Start Value } \\
{[\mathrm{mAU}]}\end{array}$ & $\begin{array}{c}\text { End Value } \\
{[\mathrm{mAU}]}\end{array}$ & $\begin{array}{c}\text { Area } \\
\text { [mAU.s] }\end{array}$ & $\begin{array}{l}\text { Height } \\
{[\mathrm{mAU}]}\end{array}$ & $\begin{array}{l}\text { Area } \\
{[\%]}\end{array}$ & $\begin{array}{l}\text { Height } \\
{[\%]}\end{array}$ \\
\hline 1 & 10,283 & 8,683 & 12,383 & $-1,728$ & $-0,768$ & 7314,201 & 659,540 & 96,3 & 93,4 \\
\hline 2 & 13,850 & 13,700 & 14,017 & $-0,185$ & 0,147 & 43,266 & 7,012 & 0,6 & 1,0 \\
\hline 3 & 15,550 & 15,433 & 15,700 & 2,802 & 1,610 & 237,184 & 39,761 & 3,1 & 5,6 \\
\hline & Total & & & & & 7594,651 & 706,314 & 100,0 & 100,0 \\
\hline
\end{tabular}


$\underline{(Z)-N^{\prime}-3 \text {-Bis-(4-(tert-butyl)phenyl)-3-hydroxypropanimidamide (16) }}$
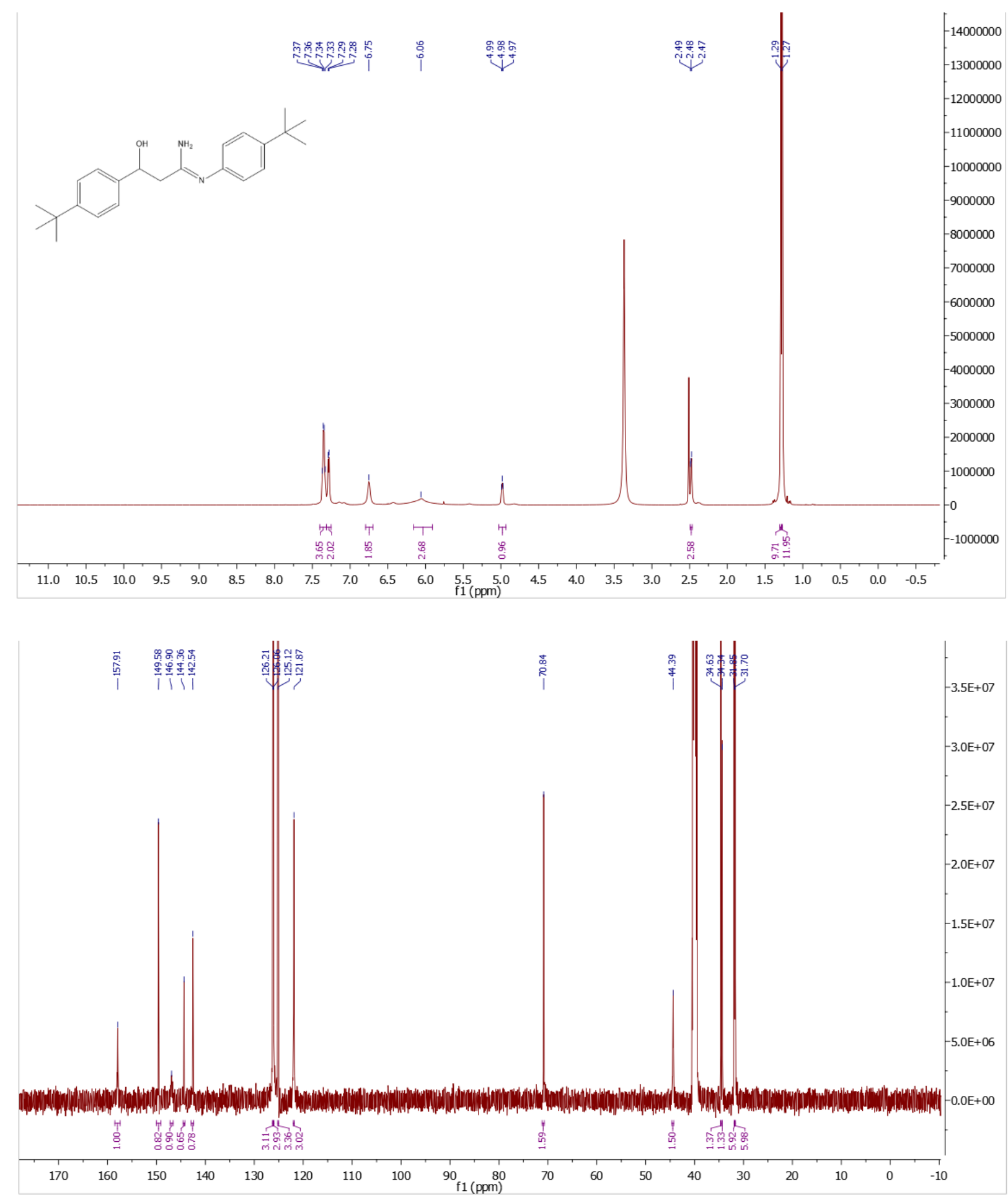


\section{(Z)-3-(3,5-Di-tert-butylphenyl)- $N^{\prime}$-(4-fluorophenyl)-3-hydroxypropanimidamide}

\section{Hydrochloride (17)}
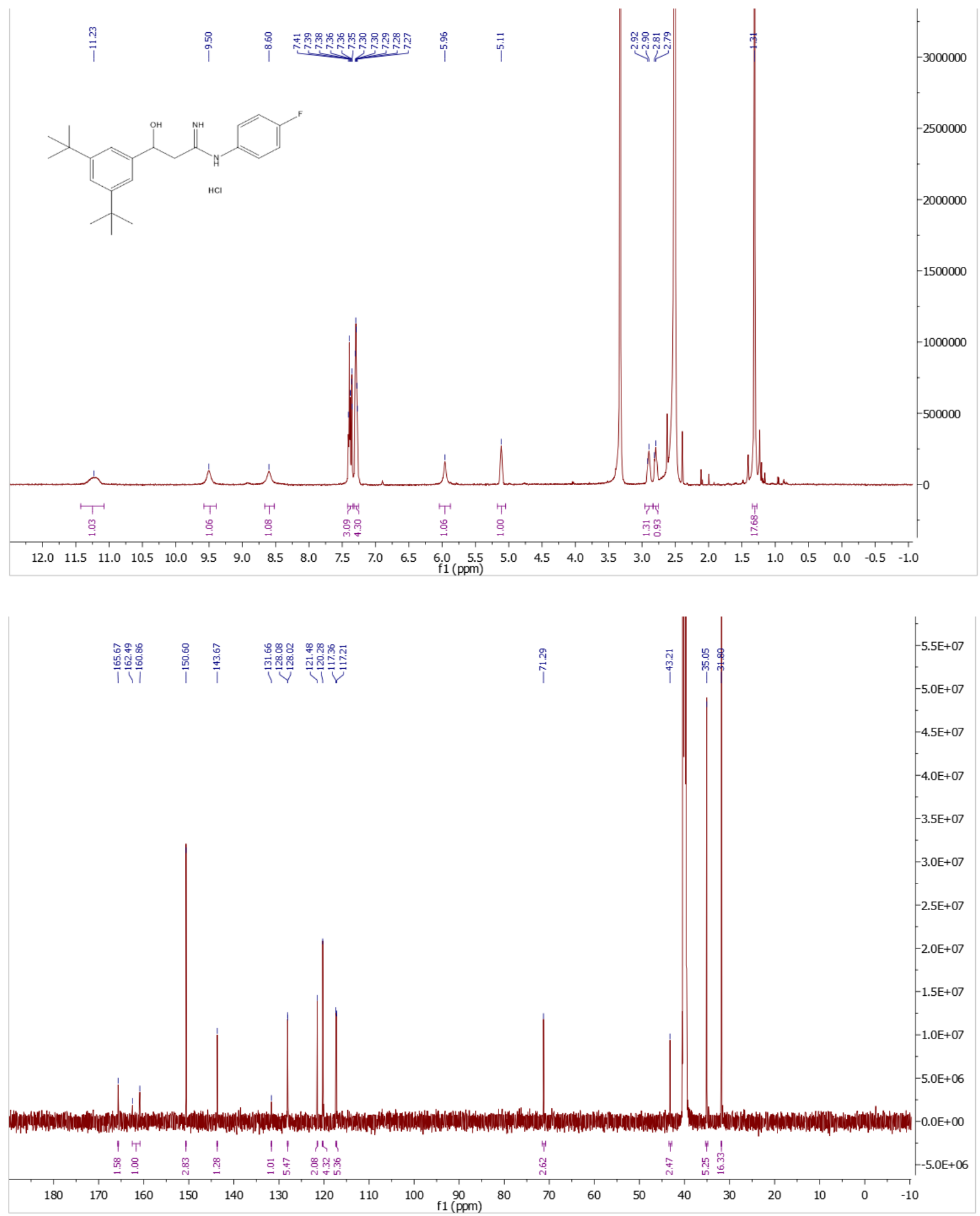


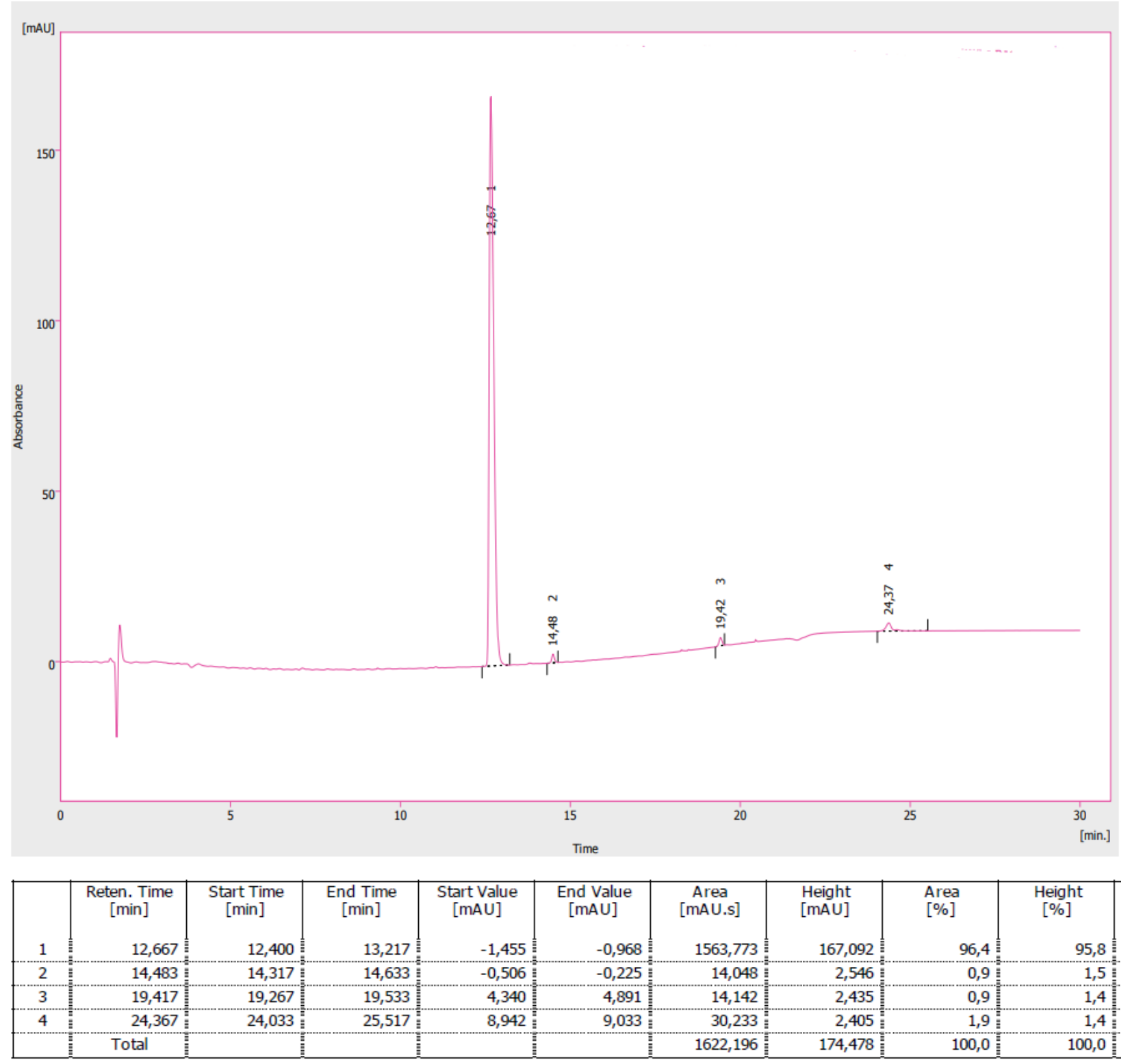




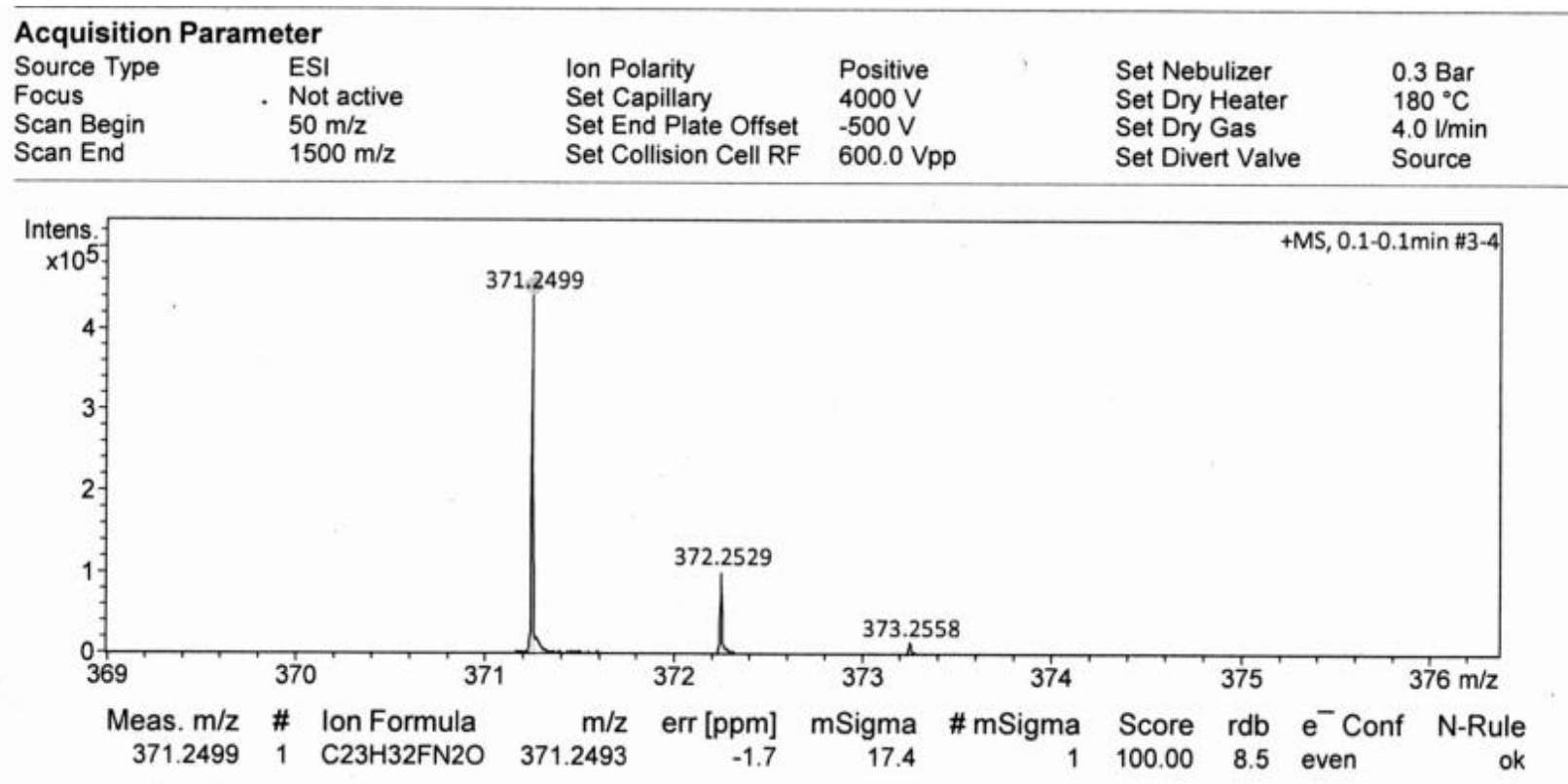




\section{(Z)- $N^{\prime}$-(4-Fluorophenyl)-3-hydroxy-3-(6-methoxyquinoline-4-yl)propanimidamide}

\section{Dihydrochloride (18)}
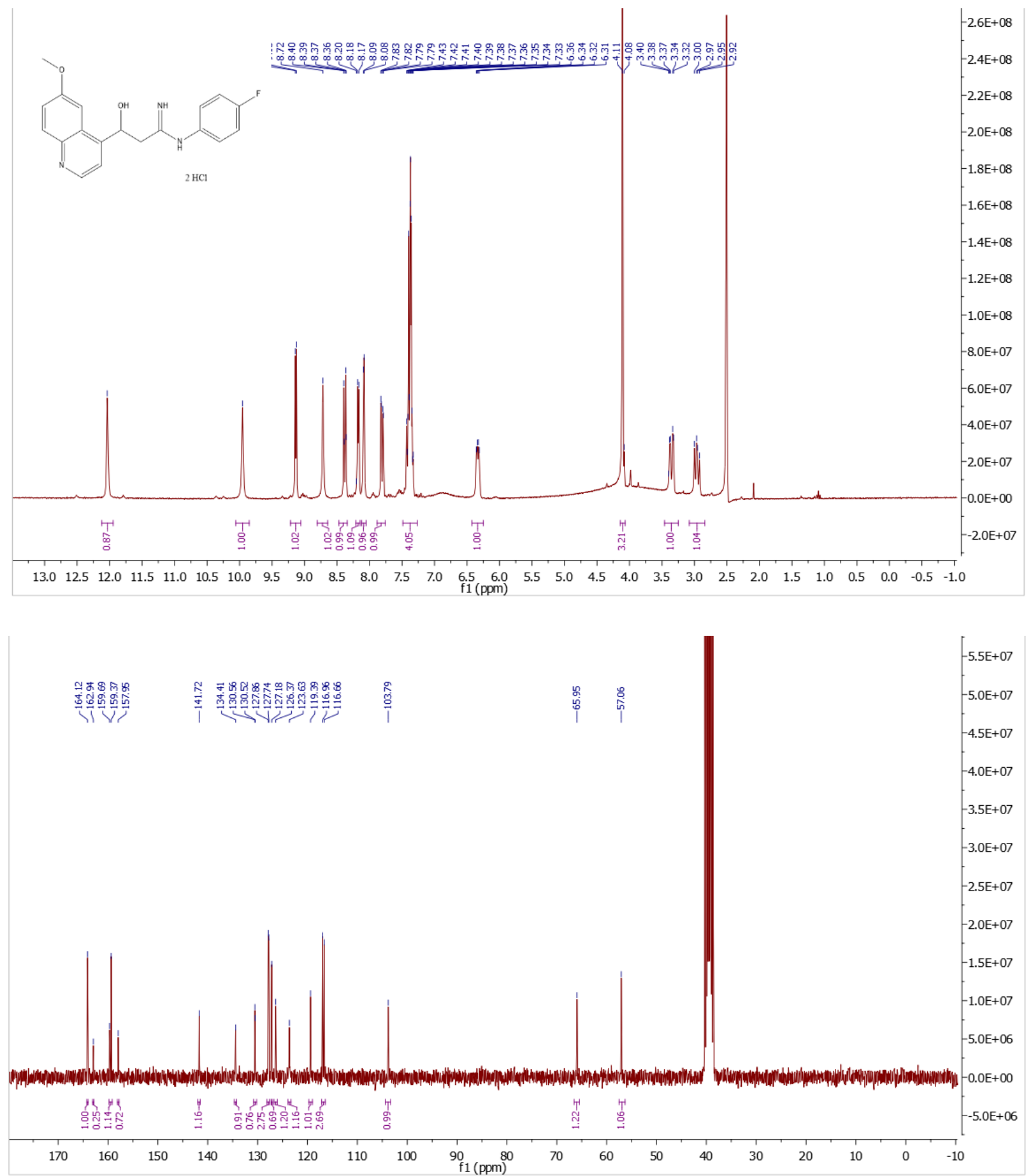


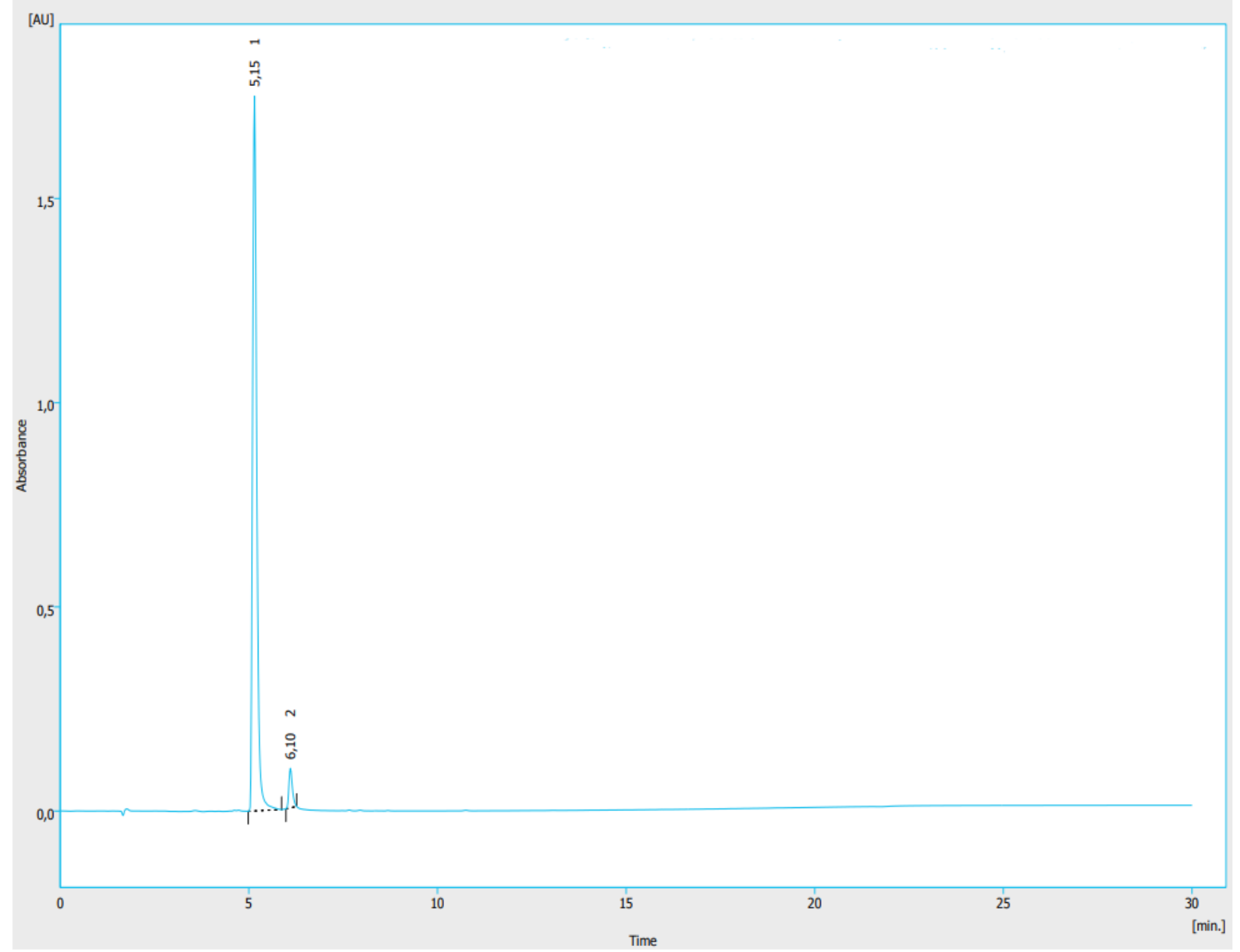

\begin{tabular}{|c|c|c|c|c|c|c|c|c|c|}
\hline & $\begin{array}{c}\text { Reten. Time } \\
{[\mathrm{min}]}\end{array}$ & $\begin{array}{c}\text { Start Time } \\
{[\mathrm{min}]}\end{array}$ & $\begin{array}{c}\text { End Time } \\
{[\mathrm{min}]}\end{array}$ & $\begin{array}{c}\text { Start Value } \\
{[\mathrm{mAU}]}\end{array}$ & $\begin{array}{c}\text { End Value } \\
{[\mathrm{mAU}]}\end{array}$ & $\begin{array}{c}\text { Area } \\
\text { [mAU.s] }\end{array}$ & $\begin{array}{l}\text { Height } \\
{[\mathrm{mAU}]}\end{array}$ & $\begin{array}{l}\text { Area } \\
{[\%]}\end{array}$ & $\begin{array}{c}\text { Height } \\
{[\%]}\end{array}$ \\
\hline 1 & 5,150 & 4,983 & 5,867 & $-0,462$ & 3,765 & 13457,828 & 1750,453 & 95,6 & 94,8 \\
\hline 2 & 6,100 & 5,983 & 6,267 & 5,486 & 11,335 & 612,322 & 96,920 & 4,4 & 5,2 \\
\hline & Total & & & & & 14070,150 & 1847,373 & 100,0 & 100,0 \\
\hline
\end{tabular}




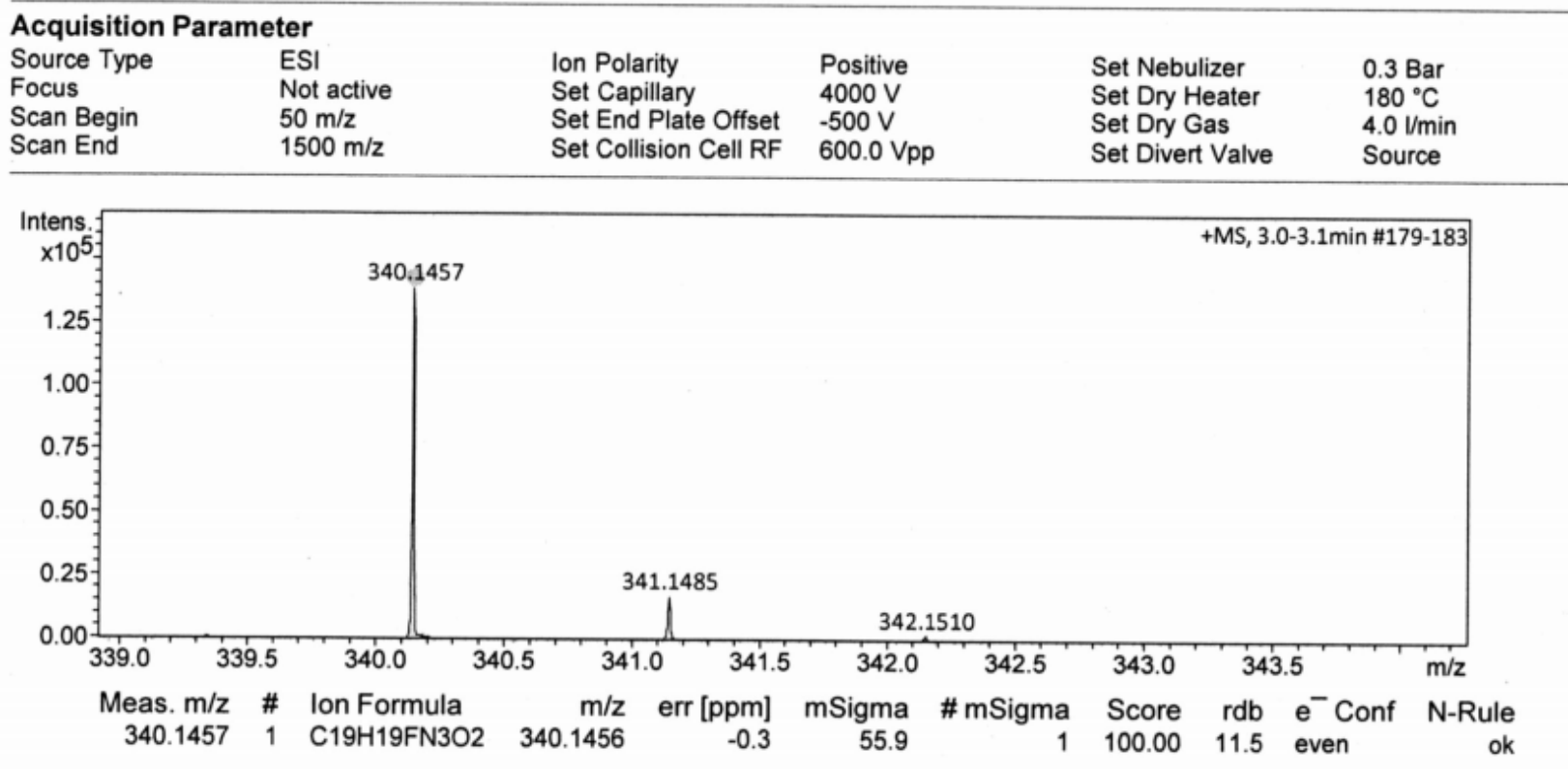




\section{$\underline{(Z)-N^{\prime} \text {-(4-Fluorophenyl)-3-hydroxy-3-(quinoline-4-yl)propanimidamide (19) }}$}
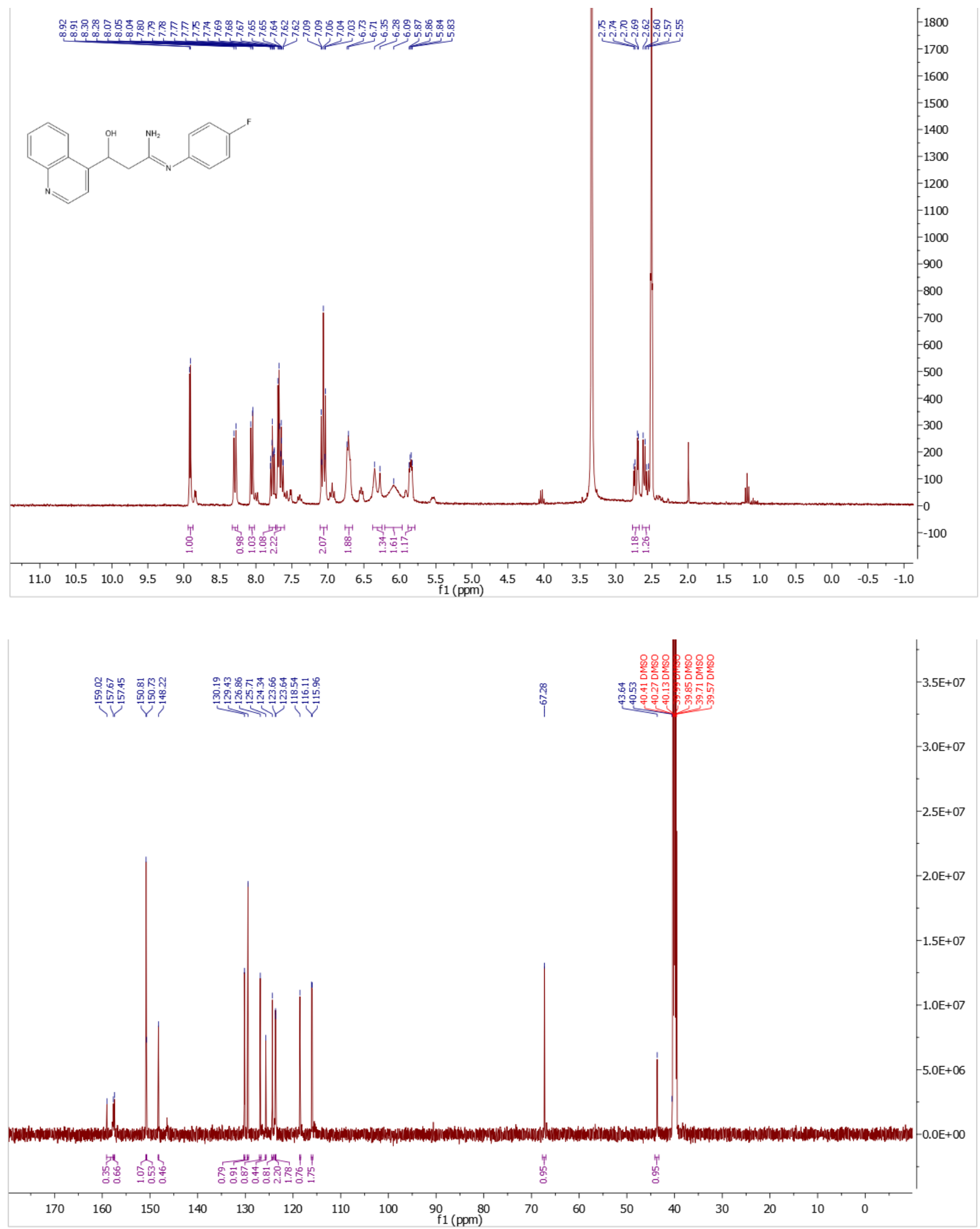


\section{$\underline{(Z)-N^{\prime} \text {-(4-Fluorophenyl)-3-hydroxy-3-(phenanthren-9-yl)propanimidamid (20) }}$}
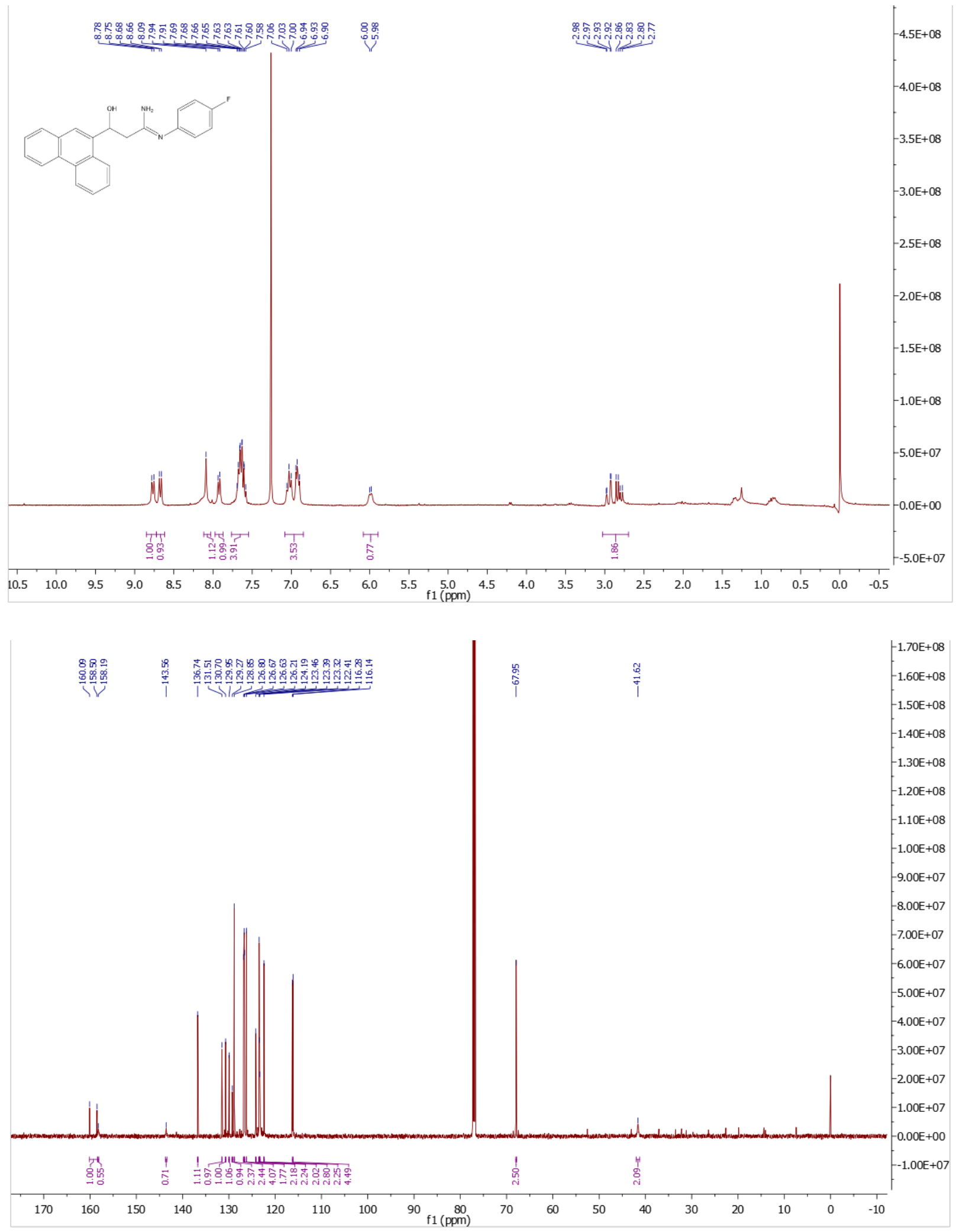


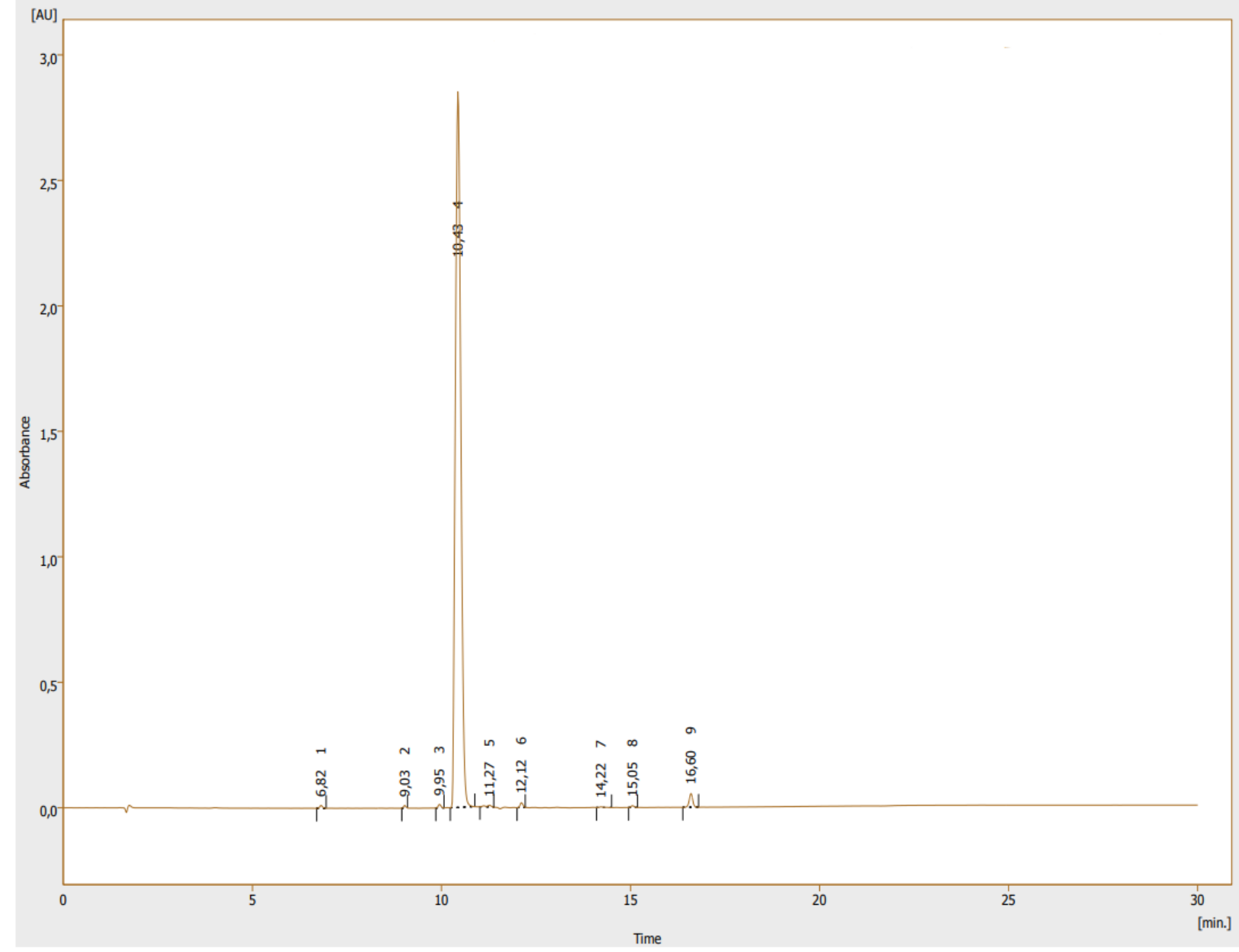

\begin{tabular}{|r|r|r|r|r|r|}
\hline & $\begin{array}{c}\text { Reten. Time } \\
{[\mathrm{min}]}\end{array}$ & $\begin{array}{c}\text { Area } \\
{[\mathrm{mAU} . \mathrm{s}]}\end{array}$ & $\begin{array}{c}\text { Height } \\
\text { [mAU] }\end{array}$ & $\begin{array}{c}\text { Area } \\
{[\%]}\end{array}$ & \multicolumn{1}{c|}{$\begin{array}{c}\text { Height } \\
{[\%]}\end{array}$} \\
\hline 1 & 6,817 & 55,448 & 11,354 & 0,2 & 0,4 \\
\hline 2 & 9,033 & 41,360 & 9,695 & 0,1 & 0,3 \\
\hline 3 & 9,950 & 70,774 & 14,279 & 0,2 & 0,5 \\
\hline 4 & 10,433 & 28681,955 & 2852,340 & 97,5 & 95,8 \\
\hline 5 & 11,267 & 67,259 & 7,100 & 0,2 & 0,2 \\
\hdashline 6 & 12,117 & 99,762 & 19,379 & 0,3 & 0,7 \\
\hline 7 & 14,217 & 23,575 & 2,671 & 0,1 & 0,1 \\
\hline 8 & 15,050 & 38,419 & 7,064 & 0,1 & 0,2 \\
\hline 9 & 16,600 & 346,838 & 54,978 & 1,2 & 1,8 \\
\hline & Total & 29425,390 & 2978,861 & 100,0 & 100,0 \\
\hline
\end{tabular}


$\underline{\text { (Z)-N-(3-((Diethylamino)methyl)-4-hydroxyphenyl)-3-hydroxy-3-(phenanthrene-9-yl)- }}$ propanimidamid Dihydrochlorid (21)
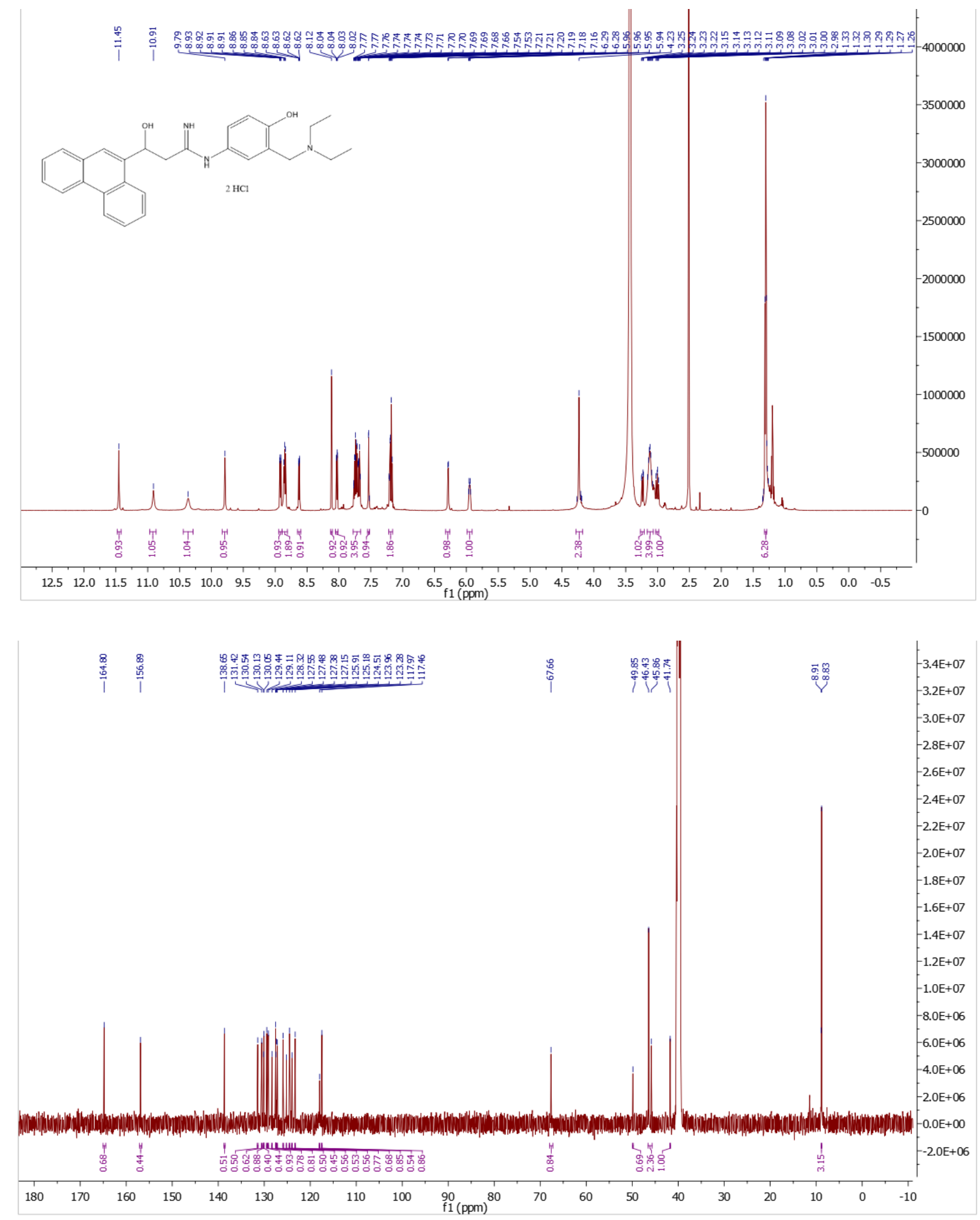


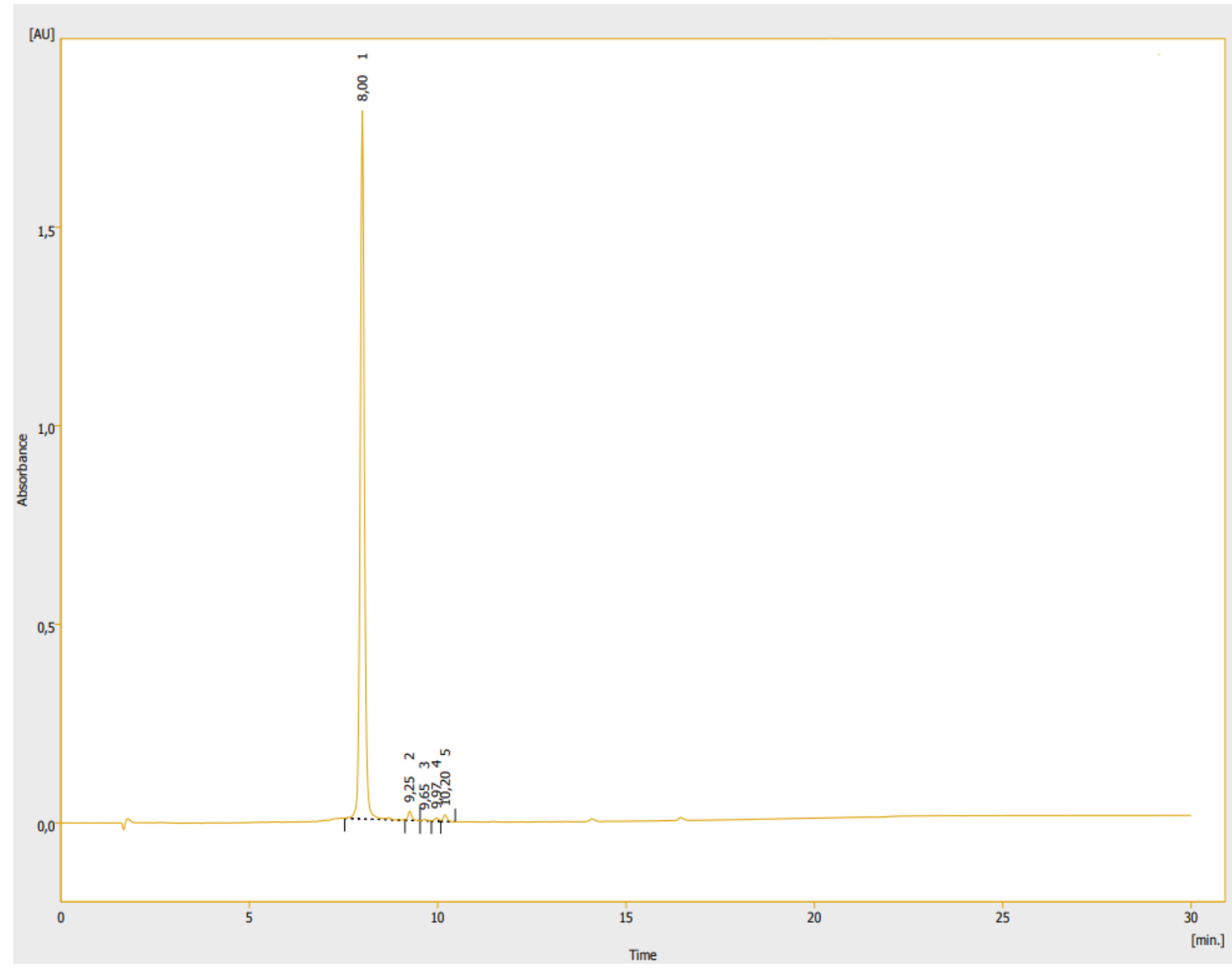

\begin{tabular}{|c|c|c|c|c|c|c|c|c|c|}
\hline & $\begin{array}{l}\text { Reten. Time } \\
\text { [min] }\end{array}$ & $\begin{array}{c}\text { Start Time } \\
{[\mathrm{min}]}\end{array}$ & $\begin{array}{c}\text { End Time } \\
{[\mathrm{min}]}\end{array}$ & $\begin{array}{c}\text { Start Value } \\
{[\mathrm{mAU}]}\end{array}$ & $\begin{array}{c}\text { End Value } \\
{[\mathrm{mAU}]}\end{array}$ & $\begin{array}{c}\text { Area } \\
\text { [mAU.s] }\end{array}$ & $\begin{array}{l}\text { Height } \\
{[\mathrm{mAU}]}\end{array}$ & $\begin{array}{l}\text { Area } \\
{[\%]}\end{array}$ & $\begin{array}{c}\text { Height } \\
{[\%]}\end{array}$ \\
\hline 1 & 8,000 & 7,533 & 9,133 & 11,430 & 6,761 & 13848,341 & 1783,418 & 97,4 & 97,2 \\
\hline 2 & 9,250 & 9,133 & 9,533 & 6,761 & 5,594 & 159,728 & 22,785 & 1,1 & 1,2 \\
\hline 3 & 9,650 & 9,533 & 9,833 & 5,594 & 4,769 & 30,006 & 3,545 & 0,2 & 0,2 \\
\hline 4 & 9,967 & 9,833 & 10,083 & 4,769 & 4,081 & 62,268 & 8,006 & 0,4 & 0,4 \\
\hline 5 & 10,200 & 10,083 & 10,467 & 4,081 & 3,026 & 123,282 & 16,595 & 0,9 & 0,9 \\
\hline & Total & & & & & 14223,624 & 1834,349 & 100,0 & 100,0 \\
\hline
\end{tabular}



propanimidamid Hydrochlorid (22)
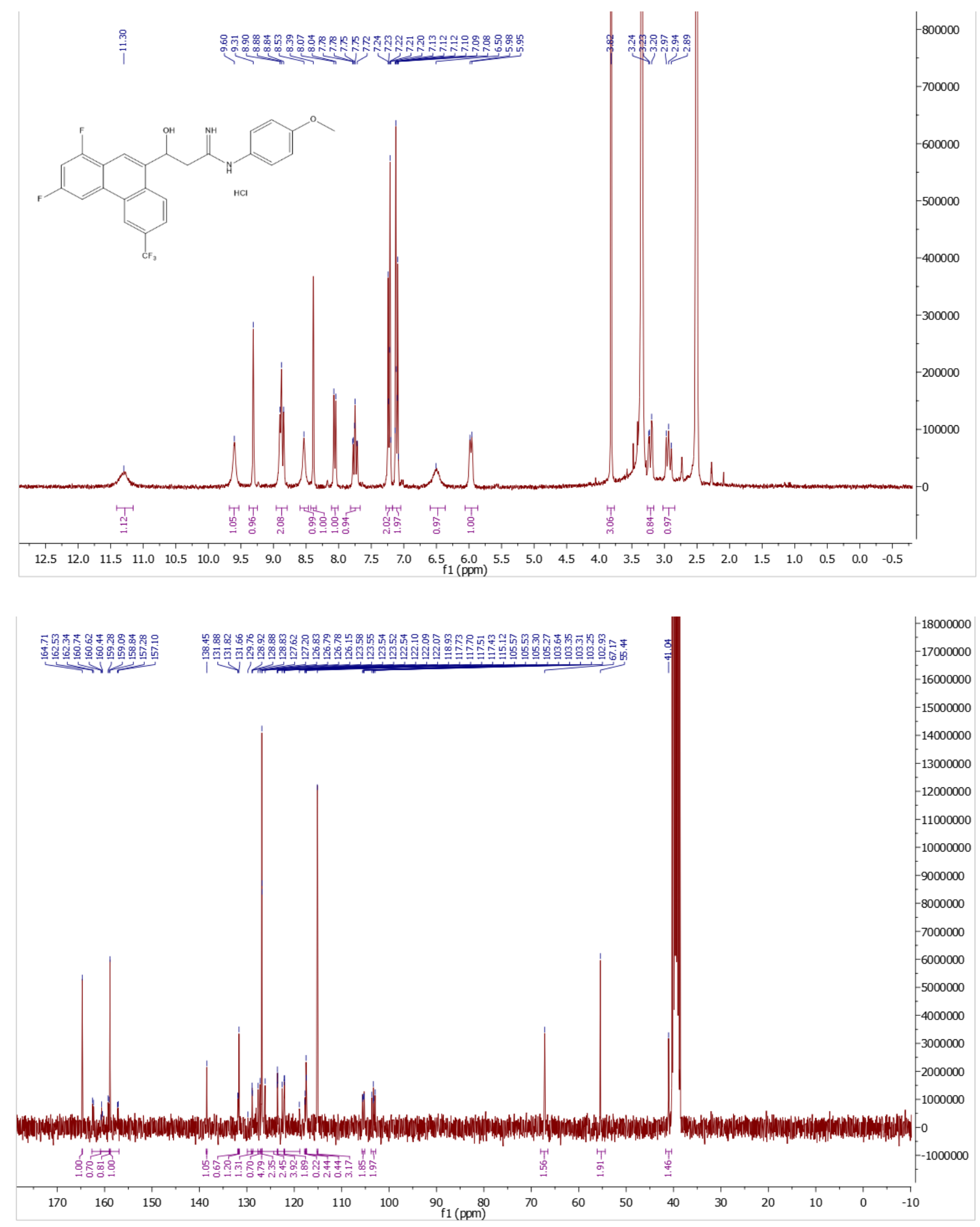


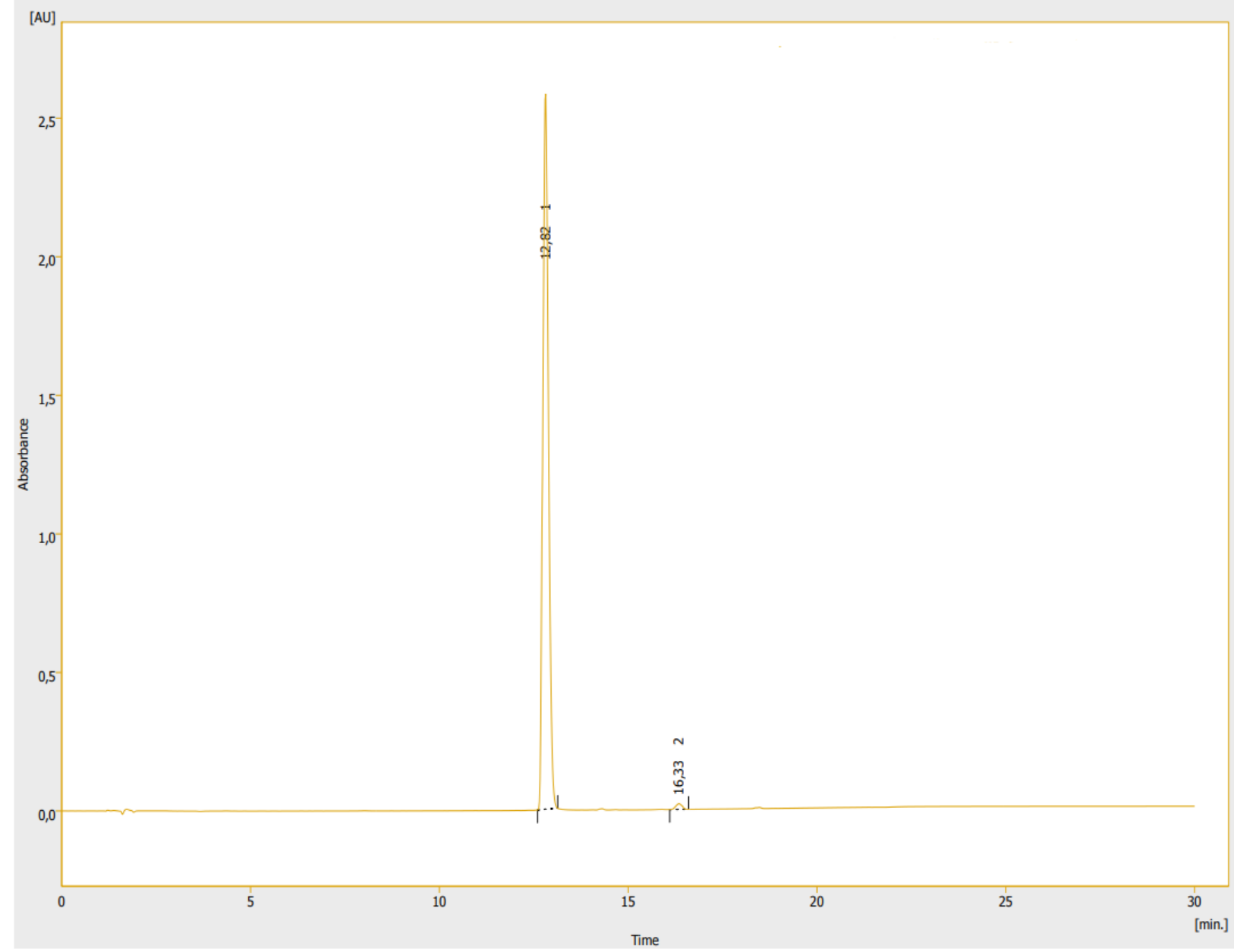

\begin{tabular}{|c|c|c|r|r|r|r|r|r|r|}
\hline & $\begin{array}{c}\text { Reten. Time } \\
{[\mathrm{min}]}\end{array}$ & $\begin{array}{c}\text { Start Time } \\
{[\mathrm{min}]}\end{array}$ & $\begin{array}{c}\text { End Time } \\
{[\mathrm{min}]}\end{array}$ & $\begin{array}{c}\text { Start Value } \\
{[\mathrm{mAU}]}\end{array}$ & $\begin{array}{c}\text { End Value } \\
{[\mathrm{mAU}]}\end{array}$ & $\begin{array}{c}\text { Area } \\
{[\mathrm{mAU} . \mathrm{s}]}\end{array}$ & $\begin{array}{c}\text { Height } \\
{[\mathrm{mAU}]}\end{array}$ & $\begin{array}{c}\text { Area } \\
{[\%]}\end{array}$ & $\begin{array}{c}\text { Height } \\
{[\%]}\end{array}$ \\
\hline 1 & 12,817 & 12,600 & 13,133 & 3,828 & 10,208 & 26791,315 & 2579,949 & 99,1 & 99,2 \\
\hline 2 & 16,333 & 16,100 & 16,600 & 5,607 & 5,960 & 237,449 & 20,299 & 0,9 & 0,8 \\
\hline & Total & & & & & 27028,764 & 2600,248 & 100,0 & 100,0 \\
\hline
\end{tabular}


(23)
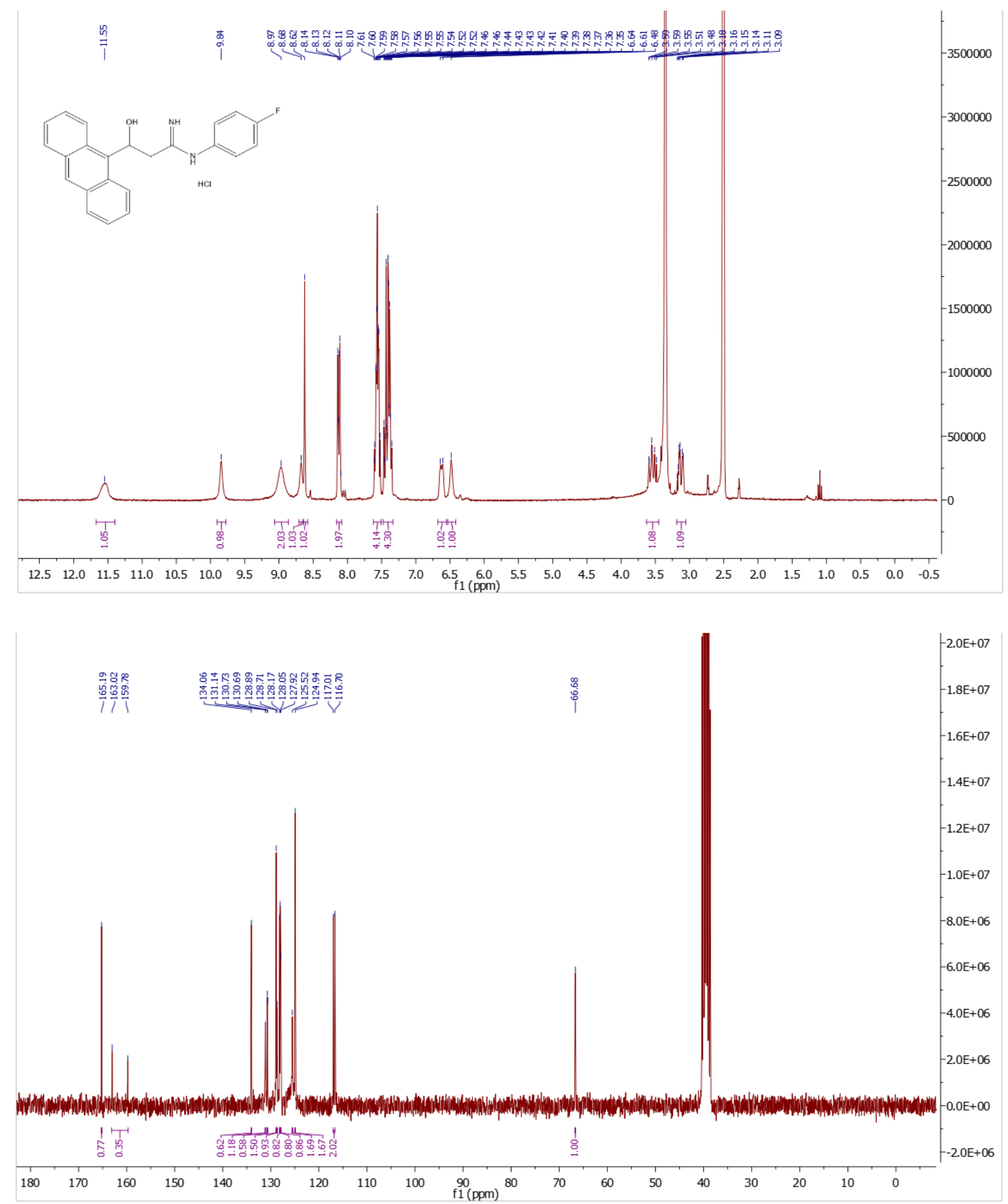


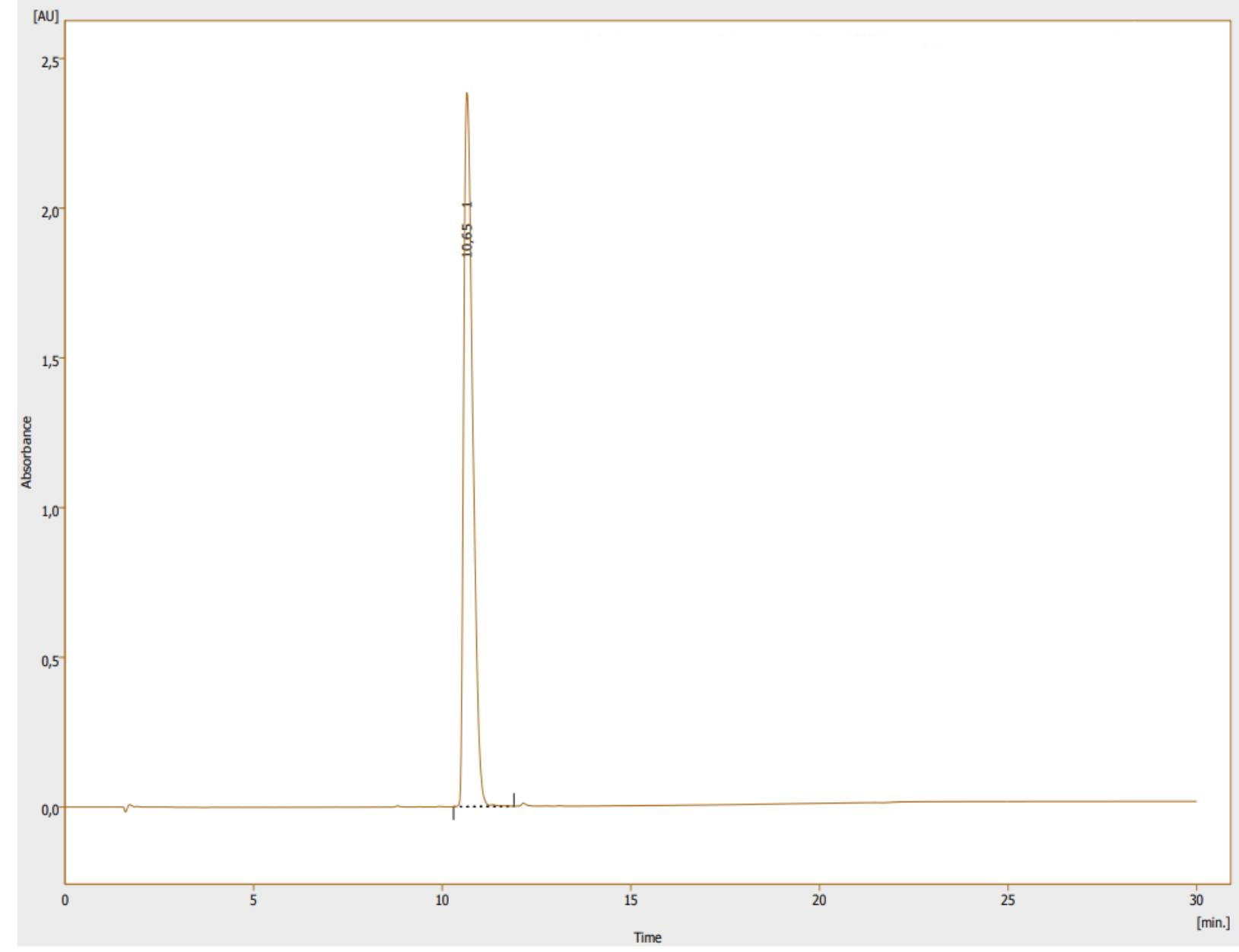

\begin{tabular}{|c|c|c|c|c|c|}
\hline & $\begin{array}{c}\text { Reten. Time } \\
{[\mathrm{min}]}\end{array}$ & $\begin{array}{c}\text { Area } \\
{[\mathrm{mAU} . \mathrm{s}]}\end{array}$ & $\begin{array}{c}\text { Height } \\
{[\mathrm{mAU}]}\end{array}$ & $\begin{array}{c}\text { Area } \\
{[\%]}\end{array}$ & $\begin{array}{c}\text { Height } \\
{[\%]}\end{array}$ \\
\hline 1 & 10,650 & 40010,496 & 2384,320 & 100,0 & 100,0 \\
\hline & Total & 40010,496 & 2384,320 & 100,0 & 100,0 \\
\hline
\end{tabular}


(Z)-3-(1,3-Dichloro-6-(trifluoromethyl)phenanthrene-9-yl)-3-hydroxy- $N^{\prime}$-(piperidin-1- yl)propanimidamide Hydrochloride (24)
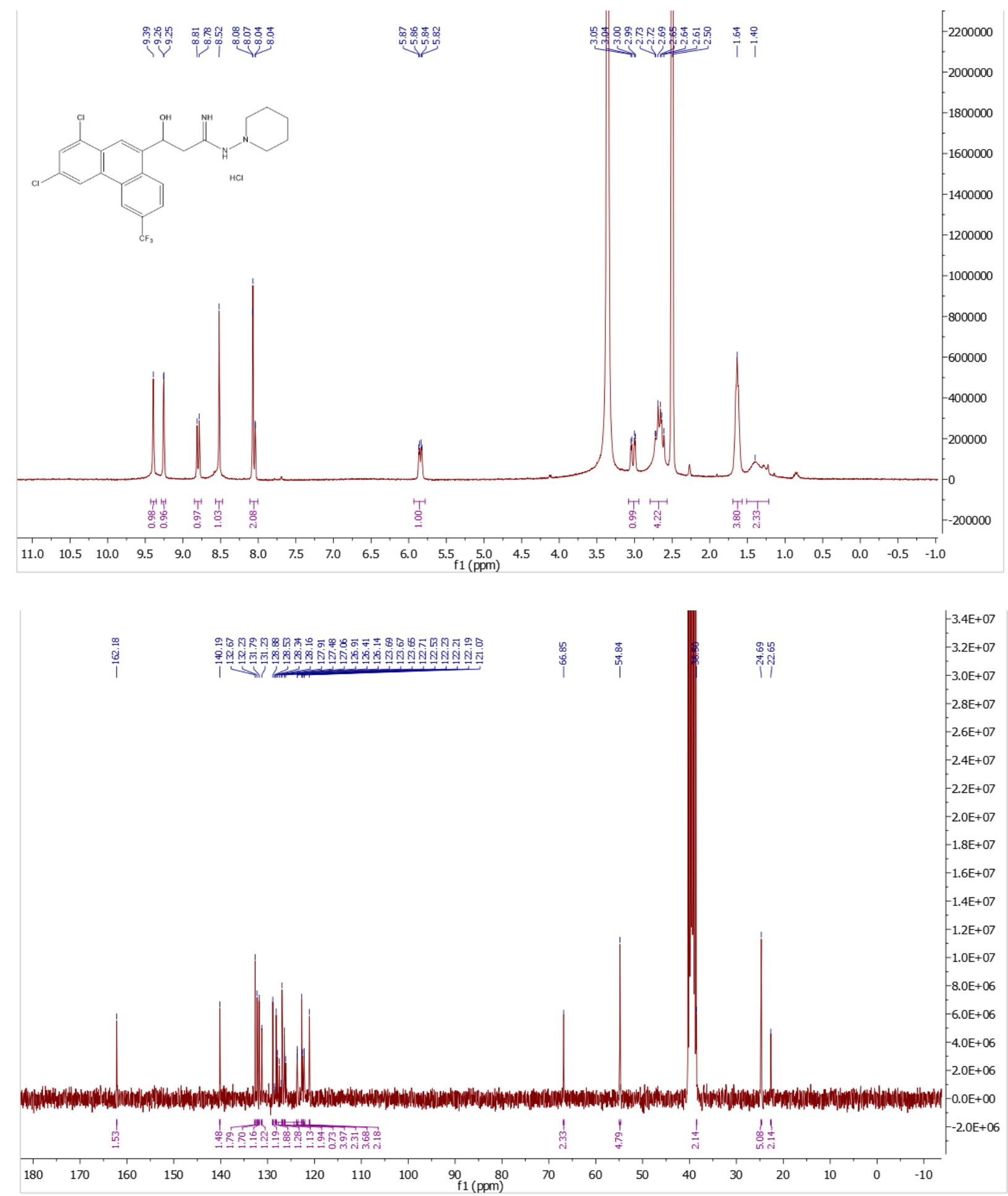


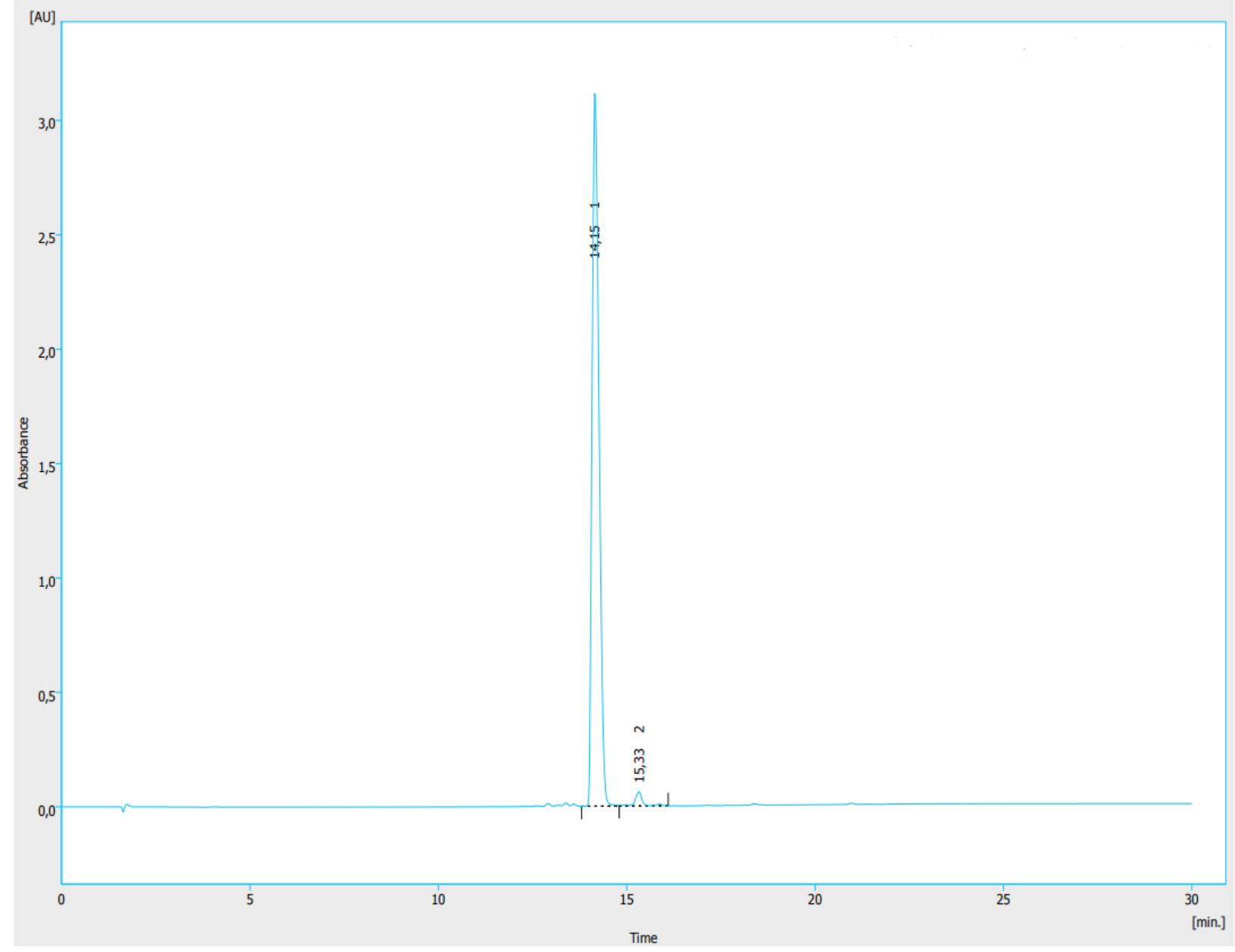

\begin{tabular}{|c|c|c|r|r|r|r|r|r|r|}
\hline & $\begin{array}{c}\text { Reten. Time } \\
{[\mathrm{min}]}\end{array}$ & $\begin{array}{c}\text { Start Time } \\
{[\mathrm{min}]}\end{array}$ & $\begin{array}{c}\text { End Time } \\
{[\mathrm{min}]}\end{array}$ & $\begin{array}{c}\text { Start Value } \\
{[\mathrm{mAU}]}\end{array}$ & $\begin{array}{c}\text { End Value } \\
{[\mathrm{mAU}]}\end{array}$ & $\begin{array}{c}\text { Area } \\
{[\mathrm{mAU} . \mathrm{s}]}\end{array}$ & $\begin{array}{c}\text { Height } \\
{[\mathrm{mAU}]}\end{array}$ & $\begin{array}{c}\text { Area } \\
{[\%]}\end{array}$ & $\begin{array}{c}\text { Height } \\
{[\%]}\end{array}$ \\
\hline 1 & 14,150 & 13,800 & 14,800 & 2,461 & 3,251 & 39710,244 & 3114,327 & 97,9 \\
\hline 2 & 15,333 & 14,800 & 16,100 & 3,251 & 4,278 & 841,370 & 61,648 & 2,1 & 98,1 \\
\hline & Total & & & & 40551,614 & 3175,976 & 100,0 \\
\hline
\end{tabular}


$\underline{\text { (Z)-3-(1,3-Dichloro-6-(trifluoromethyl)phenanthrene-9-yl)- } N^{\prime}-((4-f l u o r b e n z y l) 0 x y)-3-}$ hydroxypropanimidamide (25)
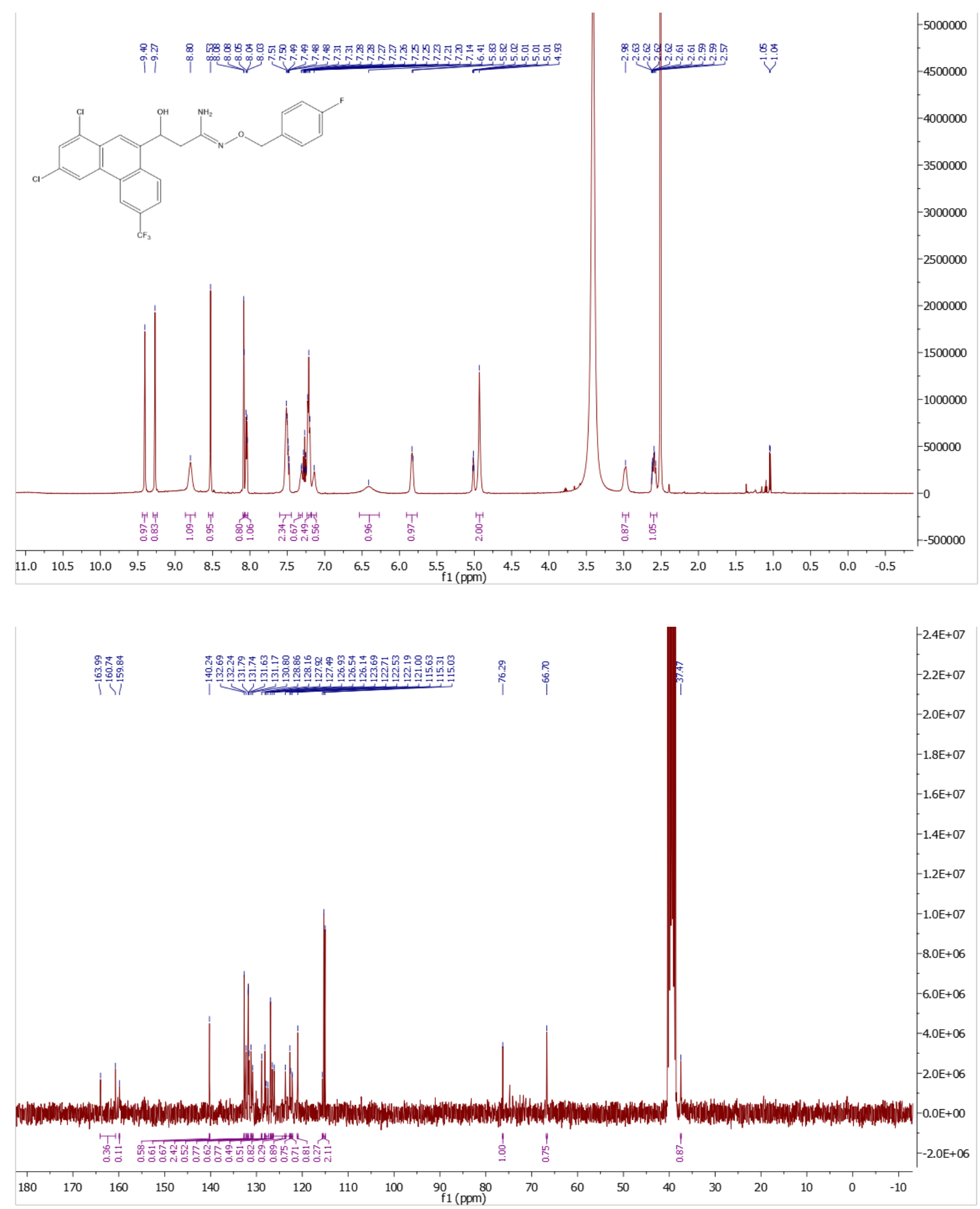


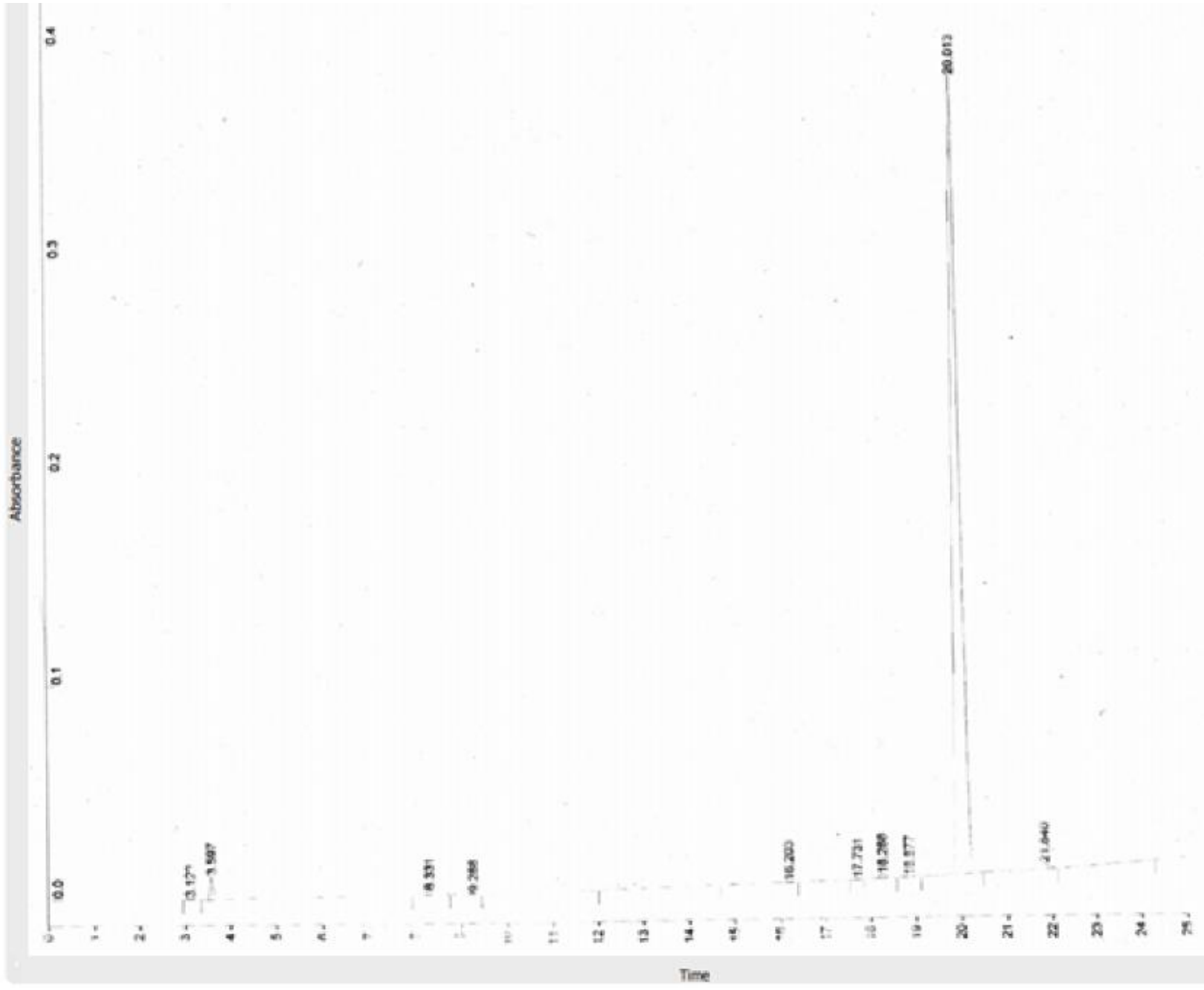

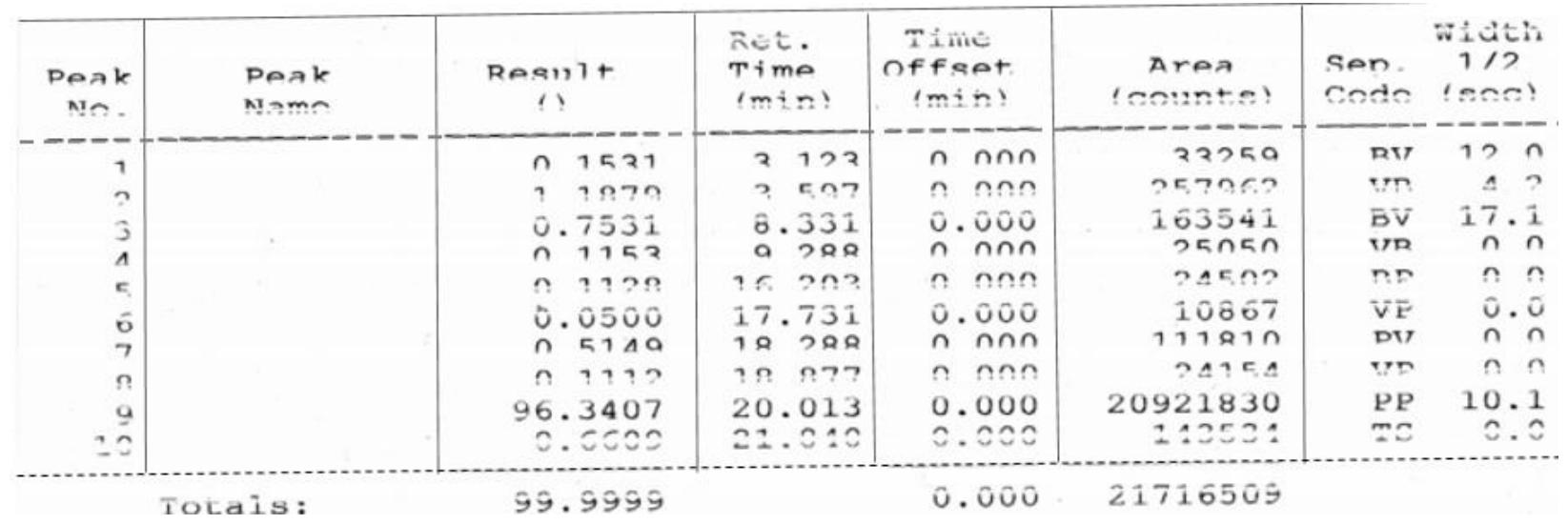




\section{REFERENCES}

(1) Leven, M.; Held, J.; Duffy, S.; Tschan, S.; Sax, S.; Kamber, J.; Frank, W.; Kuna, K.; Geffken, D.; Siethoff, C.; Barth, S.; Avery, V. M.; Wittlin, S.; Mordmüller, B.; Kurz, T. Blood schizontocidal and gametocytocidal activity of 3-hydroxy- $N^{\prime}$ arylidenepropanehydrazonamides: A new class of antiplasmodial compounds. J. Med. Chem. 2014, 57 (19), 7971-7976. DOI: 10.1021/jm500811p

(2) Leven, M.; Knaab, T. C.; Held, J.; Duffy, S.; Meister, S.; Fischli, C.; Meitzner, D.; Lehmann, U.; Lungerich, B.; Kuna, K.; Stahlke, P.; Delves, M. J.; Buchholz, M.; Winzeler, E. A.; Avery, V. M.; Mordmüller, B., Wittlin, S.; Kurz, T. 3-Hydroxy-N'arylidenepropanehydrazonamides with halo-substituted phenanthrene scaffolds cure $P$. berghei infected mice when administered perorally. J. Med. Chem. 2017, 60 (14), 60366044. DOI: 10.1021/acs.jmedchem.7b00140.

(3) Rodrigues, T.; Guedes, R. C.; dos Santos, D. J. V. A.; Carrasco, M.; Gut, J.; Rosenthal, P. J.; Moreira, R.; Lopes, F. Design, synthesis and structure-activity relationships of (1HPyridin-4-ylidene)amines as potential antimalarials. Bioorganic Med. Chem. Lett. 2009, 19 (13), 3476-3480. DOI: 10.1016/j.bmcl.2009.05.017.

(4) Noedl, H.; Bronnert, J.; Yingyuen, K.; Attlmayr, B.; Kollaritsch, H.; Fukuda, M. Simple histidine-rich protein 2 double-site sandwich enzyme-linked immunosorbent assay for use in malaria drug sensitivity testing. Antimicrob. Agents Chemother. 2005, 49 (8), 3575-3577. DOI: 10.1128/AAC.49.8.3575-3577.2005.

(5) Held, J.; Gebru, T.; Kalesse, M.; Jansen, R.; Gerth, K.; Müller, R.; Mordmüller, B. Antimalarial activity of the myxobacterial macrolide chlorotonil A. Antimicrob. Agents Chemother. 2014, 58 (11), 6378-6384. DOI: 10.1128/AAC.03326-14.

(6) R Core Team. A language and environment for statistical computing; R Foundation for statistical computing. Vienna, Austria, 2020; Available online: https://www.r-project.org/

(7) Ritz, C.; Streibig, J. C. Bioassay Analysis Using R. J. Stat. Softw. 2005, 12 (5), 1-22. DOI: 10.18637/jss.v012.i05.

(8) Borenfreund, E.; Puerner, J. A.. A simple quantitative procedure using monolayer cultures for cytotoxicity assays (HTD/NR-90). J. Tissue Cult. Methods 1985, 9 (75101), 7-8. DOI:10.1007/BF01666038 
(9) Charman, S. A.; Arbe-Barnes, S.; Bathurst, I. C.; Brun, R.; Campbell, M.; Charman, W. N.; Chiu, F. C. K.; Chollet, J.; Craft, J. C.; Creek, D. J.; Dong, Y.; Matile, H.; Maurer, M.; Morizzi, J.; Nguyen, T.; Papastogiannidis, P.; Scheurer, C.; Shackleford, D. M.; Sriraghavan, K.; Stingelin, L.; Tang, Y.; Urwyler, H.; Wang, X.; White, K. L.; Wittlin, S.; Zhou, L.; Vennerstrom, J. L. Synthetic ozonide drug candidate OZ439 offers new Hope for a single-dose cure of uncomplicated malaria. Proc. Natl. Acad. Sci. U. S. A. 2011, 108 (11), 4400-4405. DOI: 10.1073/pnas.1015762108

(10) Combrinck, J. M.; Fong, K. Y.; Gibhard, L.; Smith, P. J.; Wright, D. W.; Egan, T. J. Optimization of a multi-well colorimetric assay to determine haem species in Plasmodium falciparum in the presence of anti-malarials. Malar. J. 2015, 14 (1), 1-14. DOI: 10.1186/s12936-015-0729-9.

(11) White, J.; Dhingra, S. K.; Deng, X.; Mazouni, F. E.; Lee, M. C. S.; Afanador, G.; Lawong, A.; Tomchick, D.; Ng, C. L.; Bath, J.; Rathod, P. K.; Fidock, D. A.; Phillips, M. A. Identification and mechanistic understanding of dihydroorotate dehydrogenase point mutations in Plasmodium falciparum that confer in vitro resistance to the clinical candidate DSM265. ACS Infect Dis. 2020, 5 (1), 90-101. DOI: 10.1021/acsinfecdis.8b00211. 